NASA/TM-1998-208399

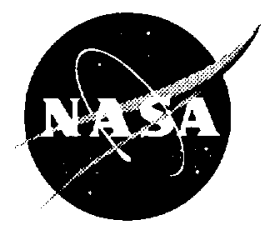

\title{
Elevated Temperature Compressive Strength Properties of Oxide Dispersion Strengthened NiAl After Cryomilling and Roasting in Nitrogen
}

J. Daniel Whittenberger

Lewis Research Center, Cleveland, Ohio

Peter Grahle and Eduard Arzt

Max-Planck-Institut für Metallforschung, Stuttgart, Germany

Mohan Hebsur

Ohio Aerospace Institute, Cleveland, Ohio

National Aeronautics and

Space Administration

Lewis Research Center 


\section{Acknowledgments}

JDW would like to acknowledge the financial support of the Alexander von Humboldt foundation during his stay at Max-Planck-Institut für Metallforschung, Stuttgart.

Available from

NASA Center for Aerospace Information 7121 Standard Drive Hanover, MD 21076

Price Code: A03
National Technical Information Service 5287 Port Royal Road Springfield, VA 22100 Price Code: A03 


\title{
ELEVATED TEMPERATURE COMPRESSIVE STRENGTH PROPERTIES OF OXIDE DISPERSION STRENGTHENED NiAl AFTER CRYOMILLING AND ROASTING IN NITROGEN
}

\author{
J. Daniel Whittenberger \\ National Aeronautics and Space Administration \\ Lewis Research Center \\ Cleveland, Ohio 44135 \\ Peter Grahle and Eduard Arzt \\ Max-Planck-Institut für Metallforschung \\ Stuttgart, Germany \\ and \\ Mohan Hebsur \\ Ohio Aerospace Institute \\ Cleveland, Ohio 44142
}

\begin{abstract}
SUMMARY
In an effort to superimpose two different elevated temperature strengthening mechanisms in NiAl, several lots of oxide dispersion strengthened (ODS) NiAl powder have been cryomilled in liquid nitrogen to introduce AIN particles at the grain boundaries. As an alternative to cryomilling, one lot of ODS NiAl was roasted in nitrogen to produce AIN. Both techniques resulted in hot extruded AIN-strengthened, ODS NiAl alloys which were stronger than the base ODS NiAl between 1200 and $1400 \mathrm{~K}$. However neither the cryomilled nor the $\mathrm{N}_{2}$-roasted ODS NiAl alloys were as strong as cryomilled binary NiAl containing like amounts of AIN. The reason(s) for the relative weakness of cryomilled ODS NiAl is not certain; however the lack of superior strength in $\mathrm{N}_{2}$-roasted ODS NiAl is probably due to its relatively large AIN particles.
\end{abstract}

\section{INTRODUCTION}

One serious difficulty with the use of the $\mathrm{B} 2$ intermetallic $\mathrm{NiAl}$ as a high temperature structural material is its inherent lack of strength at temperature. Currently two powder metallurgy techniques are now available which can induce strength levels approaching those of simple Ni-base superalloys: a 'traditional' mechanical alloying to produce an oxide dispersion strengthened (ODS) $\mathrm{NiAl}$ (ref. 1) and high intensity milling of $\mathrm{NiAl}$ powder in liquid nitrogen-the cryomilling process (ref. 2). These two powder processes are intriguing in the sense that they appear to involve completely different strengthening mechanisms; hence they offer the potential for superpositioning.

Through mechanical alloying (MA) mixtures of Al-rich and Ni-rich master alloys with $\mathrm{Y}_{2} \mathrm{O}_{3}$, Zöltzer (ref. 3) was able to successfully incorporate oxides uniformly throughout a NiAl matrix. Consolidation (refs. 1 and 4) resulted in a very fine grain sized $(\sim 1 \mu \mathrm{m})$ material reinforced with $\mathrm{Y}_{3} \mathrm{Al}_{5} \mathrm{O}_{12}$ dispersoids with a median diameter of $\sim 30 \mathrm{~nm}$ (ref. 5), and testing demonstrated that this material exhibited a 50 percent strength advantage over binary $\mathrm{NiAl}$ at $1300 \mathrm{~K}$ (ref. 4). This relatively low improvement in strength was traced to the small grain size of the densified materials, as even a simple heat treatment which grew the grains to $10 \mu \mathrm{m}$ tripled the $1300 \mathrm{~K}$ creep strength (ref. 4). Following the history of metallic ODS alloys, Grahle et al. (refs. 1, 5 and 6) developed thermomechanical processing schedules to force large scale grain growth, and such materials exhibited improved creep properties even though the medium dispersoid diameter tripled to $\sim 95 \mathrm{~nm}$. Thus it appears that oxide dispersion strengthening can harden the NiAl matrix but leaves the grain boundaries relatively weak.

Concurrent with study of ODS NiAl, it was discovered (refs. 7 and 8) that high intensity grinding of prealloyed, binary NiAl powder in liquid nitrogen led to the formation of AlN particles on the surfaces of the powder fragments. Following densification, the material possessed a core and mantle microstructure, where micrometer size NiAl cores 
were surrounded by a thin mantle composed of $\sim 25 \mathrm{~nm}$ diameter AlN particles and $\sim 100 \mathrm{~nm}$ NiAl grains (refs. 9 and 10). Subsequent mechanical testing demonstrated that this heterogeneous, small grain size microstructure was capable of yielding very good creep properties under both compressive and tensile conditions (ref. 11). Clearly in this case strength must be the result of the mantle regions as the NiAl cores are devoid of any reinforcing second phase particles. Therefore cryomilled $\mathrm{NiAl}$ can be thought to possess strong grain boundaries (i.e. mantle) and weak grain interiors (cores).

Because cryomilling can, in essence, harden the grain boundary regions in NiAl and as-consolidated ODS NiAl suffers from relatively easy grain boundary deformation, these two techniques appeared ideal for superimposition in a single $\mathrm{NiAl}$ alloy. If successful, the weakness of each individual technique would be counteracted by the strength of the other technique. To this end a joint program between the Max-Planck-Institut für Metallforschung (MPI) and the NASA-Lewis Research Center (LeRC) was initiated to combine mechanical alloying with cryomilling and produce a dispersion strengthened, AlN particulate reinforced $\mathrm{NiAl}$ alloy for use at elevated temperatures.

This report presents the results of a study of the elevated temperature compressive properties of two heats of ODS NiAl powder after cryomilling and hot extrusion and a third heat of ODS NiAl which was tested in three conditions: (1) directly hot extruded, (2) roasted in nitrogen followed by hot extrusion, and (3) cryomilled followed by hot extrusion. This latter set of conditions allowed the direct comparison of the mechanical properties of the base ODS NiAl alloy to those after cryomilling and after an alternative method $\left(\mathrm{N}_{2}\right.$ roasting of the same ODS alloy, (ref. 4)) which also produced AIN. Part of this program was conducted at the Institut für Werkstoffwissenschaft, Max-Planck-Institut für Metallforschung, Stuttgart, Germany during one author's (JDW) stay at this institute, and the effort was completed at the NASA-Lewis Research Center, Cleveland, OH. Preliminary results were reported at the Fall '96 MRS meeting in Boston, MA and have been published in the symposium proceedings (ref. 12).

\section{EXPERIMENTAL PROCEDURES}

Mechanically alloying was undertaken at Metallgesellschaft AG, Frankfurt utilizing an evacuated centrifugal vibratory ball mill (refs. 3 and 6) with a water-cooled, 20 liter capacity, cylindrical stainless steel milling chamber ( $260 \mathrm{~mm}$ diameter by $380 \mathrm{~mm}$ in height). A typical charge involved $56 \mathrm{~kg}$ of $18 \mathrm{~mm}$ diameter steel balls and $5 \mathrm{~kg}$ of appropriate mixtures of $\mathrm{Ni}_{3} \mathrm{Al}$ and $\mathrm{Ni}-70$ at $\% \mathrm{Al}$ plus yttria powders designed to yield stiochiometric $\mathrm{Ni}-50 \mathrm{Al}+1$ or $3 \mathrm{vol} \% \mathrm{Y}_{2} \mathrm{O}_{3}$ \{identified as IP 6000/1 or IP 6000/3, respectively (ref. 4)\} as the final product. For the present study three batches of ODS NiAl powder were utilized: following the MPI designations, they are heat $\mathrm{ZS}$ and a mixed batch \{heats Z12+Z13+Z6/1\} of IP $6000 / 1$ along with a single heat of IP $6000 / 3$ (Z15). Both Z15 and the mixed batch $\{Z 12+Z 13+Z 6 / 1\}$ were mechanically alloyed for a total of $50 \mathrm{~h}$, while $\mathrm{Z5}$ was only milled for $32 \mathrm{~h}$.

Because only a limited amount of powder from $Z 15$ and the mixed batch $\{Z 12+Z 13+Z 6 / 1\}$ was available, both were cryomilled in a Union Process Model 1S attritor which was enclosed in a slightly positive nitrogen pressure environmental chamber. The attritor vessel was loaded in air with $1 \mathrm{~kg}$ of mechanically alloyed ODS NiAl powder and $\sim 15 \mathrm{~kg}$ of hardened steel grinding media and then fixed in-place in the attritor. After closing the environmental chamber, flow of liquid nitrogen through the cooling jacket of the attritor vessel was initiated. Once the contents of the vessel reached cryogenic temperatures, it was filled with liquid nitrogen to create a nitrogen/grinding media/ NiAl powder slurry, and milling was initiated. During milling liquid nitrogen was continuously circulated through the cooling jacket and was intermittently introduced into the vessel to maintain a constant slurry level. All cryomilling runs were conducted for $4 \mathrm{~h}$; after which the attritor vessel was allowed to warm to room temperature, and the environmental chamber open to the atmosphere. Once the cryomilled power was separated from the grinding media, it was placed in $75 \mathrm{~mm}$ diameter superalloy lined steel cans, vacuum sealed and hot extruded at $1505 \mathrm{~K}$ with a reduction ratio of $8: 1$.

With three $\mathrm{kg}$ of the IP $6000 / 1 \mathrm{Z5}$ being available for use, it was divided into three equal lots. One of these lots was simply vacuum canned in a $75 \mathrm{~mm}$ diameter superalloy lined steel can and hot extruded at $1505 \mathrm{~K}$ through an 8:1 reduction ratio die. The second lot was cryomilled and hot extruded following the procedures described above. The remaining $\mathrm{kg}$ of Z5 was annealed in pure nitrogen gas for $2 \mathrm{~h}$ at $1473 \mathrm{~K}$ as previous work (ref. 4) had shown that AlN could also be formed on $\mathrm{NiAl}$ powder by roasting in $\mathrm{N}_{2}$. If simple roasting of the ODS NiAl-base powder could provide effective grain boundary strengthening in as-consolidated materials, this would be a much more cost effective procedure than cryomilling. Because of the small capacity of the furnace, multiple roasting runs were required. The chronology of each run consisted of slowly evacuating the furnace which contained 50 to $100 \mathrm{~g}$ of MA'ed powder in pure $\mathrm{Al}_{2} \mathrm{O}_{3}$ crucibles, inducing a $67 \mathrm{kPa}$ pressure of pure nitrogen into the furnace, rapidly 
heating to $1473 \mathrm{~K}$ in about $900 \mathrm{~s}$, holding the furnace temperature and gas pressure for $2 \mathrm{~h}$, followed by furnace cooling in nitrogen. The product from each of the roasting runs was then blended together, placed in a $75 \mathrm{~mm}$ superalloy lined steel can and hot extruded at $1505 \mathrm{~K}-8: 1$.

Following hot extrusion, samples for chemical and X-ray analyses were taken from each extruded bar. The composition of the densified alloys was determined through inductively coupled plasma emission spectrometry for the metallic elements and combustion plus extraction methods for $\mathrm{C}, \mathrm{N}$ and $\mathrm{O}$.

Cylindrical compression test specimens were directly electrodischarged machined from the hot extruded alloys with the long axis of the cylinders parallel to the extrusion direction. Two samples geometries were utilized: $9 \mathrm{~mm}$ diameter by $18 \mathrm{~mm}$ long right cylinders for use under multiple constant load or multiple constant velocity conditions and $5 \mathrm{~mm}$ diameter by $10 \mathrm{~mm}$ long right cylinders for single constant velocity or constant load conditions. All samples were tested in the as-electrodischarged machined surface condition.

Multiple constant load testing was conducted at elevated temperature in air at MPI utilizing self-induction heating of the large test specimen in combination with a servoload cell controlled electromechancial test machine. Temperature was monitored and controlled through Pt/Pt-Rh thermocouples spot welded to the sample, while strain was measured by an alumina high temperature extensometer with a $11 \mathrm{~mm}$ gage in direct contact with the sample. During testing output from both the extensometer and load cell were recorded by a multipen strip chart recorder. Each sample was tested under a number of conditions, where both temperature and applied load were varied. In the case of a change in stress at a constant temperature, the applied load was rapidly increased or decreased on the fly; however if temperature were being changed, the stress was first reduced to a small value (a few MPa) to maintain contact between the rams and sample, the sample heated to its new temperature, and once the temperature had equilibrated the stress was rapidly increased to the desired value. Following the conclusion of testing, results were manually extracted from the charts and entered into a spreadsheet for analysis. For purposes of analyzing the flow stress-strain rate-temperature behavior of the materials; the steady state deformation rate and average stress over the steady state regime were utilized as measures of the strain rate and flow stress respectively. A complete description of the experimental setup is given in reference 5 .

Several large samples were also subjected to multiple constant velocity testing in a universal testing machine. In all these cases the samples were tested at a constant temperature in air with the initial velocity set a low rate such that a few percent strain could be accumulate over night; the next morning the velocity was then increased an order of magnitude until a few more percent strain were obtained; this procedure was then repeated two more times. Additional constant velocity testing was undertaken with the smaller $5 \mathrm{~mm}$ diameter by $10 \mathrm{~mm}$ tall test samples. In these cases the samples were compressed in air between 1100 to $1400 \mathrm{~K}$, where each test was conducted to completion under a single crosshead speed. For both the multi- and single constant velocity experiments, the autographically recorded load-time charts were converted to true stresses, strains and strain rate assuming conservation of volume and the offset method. The stress and strain rate at 1 percent deformation following each change in crosshead velocity were utilized as measures of the flow stress and strain rate to determine the temperature-stress-deformation rate behavior of the materials.

A number of the $5 \mathrm{~mm}$ diameter by $10 \mathrm{~mm}$ tall samples were also tested under constant load compressive creep conditions in lever arm test machines. Deformation was determined as a function of time by measuring the relative positions of ceramic push bars applying a constant load to the specimen (ref. 13). Contraction-time data were normalized with respect to the final specimen length and converted into true stresses and strains. Steady state creep rates and the average stress over the steady state portion of the creep curves were used in the temperature-stressdeformation rate analysis for each material.

\section{RESULTS}

\section{As-Densified Materials}

Composition/phases. - Intensity-diffraction angle plots from X-ray phase identification analysis of the three different forms of hot extruded IP 6000/1 Z5 have been presented in reference 12. In summary they indicated only $\mathrm{NiAl}$ existed in the base ODS alloy; NiAl, AIN and possibly $\gamma^{\prime}$ were present in the $\mathrm{N}_{2}$-roasted material; and NiAl, AlN and traces of $\mathrm{Al}_{2} \mathrm{O}_{3}$ co-existed in the cryomilled version. These data confirmed the expected behavior as a function of processing, where the $\mathrm{Y}_{3} \mathrm{Al}_{5} \mathrm{O}_{12}$ content was too low to be visible by $\mathrm{X}$-ray techniques, and AIN was formed by both simple nitrogen roasting and cryomilling. Based on the X-ray results for cryomilled IP $6000 / 1 \mathrm{Z5}$, 
it was presumed that cryomilling produced AIN along with some $\mathrm{Al}_{2} \mathrm{O}_{3}$ in the second lot of IP 6000/1 $\{Z 12+Z 13+Z 6 / 1\}$ and in IP 6000/3 $\{Z 15\}$.

The approximate compositions for all the materials are given in table $\mathrm{I}$, where the matrix chemistry is given in atom percent and the second phase content in volume percent. In these latter calculations all yttria was assumed to react with $\mathrm{Al}$ and $\mathrm{O}$ to form $\mathrm{Y}_{3} \mathrm{Al}_{5} \mathrm{O}_{12}$ during thermomechanical exposure (refs. 1 and 5), while $\mathrm{N}$ combined with $A l$ to produce $A I N$ and the remaining $O$ reacted to form alumina.

The alloy chemistries in table 1 reveal that the chemistry of all the matrices is Ni-rich rather than the originally intended $\mathrm{Ni}$-50Al composition, even in the base form of Z5. This discrepancy is, at least, partially due to the transformation of $\mathrm{Y}_{2} \mathrm{O}_{3}$ to $\mathrm{Y}_{3} \mathrm{Al}_{5} \mathrm{O}_{12}$ and the formation of $\mathrm{AIN}$ and $\mathrm{Al}_{2} \mathrm{O}_{3}$. Roasting of the IP 6000/1 Z5 in nitrogen for $2 \mathrm{~h}$ at $1473 \mathrm{~K}$ resulted in a very large nitrogen pick-up ( $3.4 \mathrm{wt} \%$ versus $0.16 \mathrm{wt} \%$ after $\mathrm{MA}$ ) which led to a material with almost $18 \mathrm{vol} \% \mathrm{AlN}$ in a very Al-deficient NiAl matrix. The amount of AlN formed during a $4 \mathrm{~h}$ cryomilling run of IP 6000/1 Z5 was less than half that produced by the $\mathrm{N}_{2}$-roast; as a result the matrix of cryomilled IP $6000 / 1$ $\mathrm{Z} 5$ contains more Al. The second phase content of cryomilled IP $6000 / 1\{\mathrm{Z} 12+Z 13+\mathrm{Z} 6 / 1\}$ is in good agreement with that obtained for cryomilled IP 6000/1 Z5; however the Fe level in the matrix of $\{Z 12+Z 13+Z 6 / 1\}$ is twice that of Z5. The $\mathrm{Y}_{3} \mathrm{Al}_{5} \mathrm{O}_{12}$ content of cryomilled IP 6000/3 Z15 is three times those of cryomilled IP 6000/1 Z5 and $\{\mathrm{Z12}+\mathrm{Z13}+\mathrm{Z6} / 1\}$; this large difference in $\mathrm{Y}_{3} \mathrm{Al}_{5} \mathrm{O}_{12}$ content was expected, since $\mathrm{Z15}$ was initially mechanically alloyed with a 3 wt \% yttria addition while $\mathrm{Z5}$ and $\{\mathrm{Z} 12+\mathrm{Z} 13+\mathrm{Z} 6 / 1\}$ were $\mathrm{MA}$ 'ed with only $1 \mathrm{wt} \% \mathrm{Y}_{2} \mathrm{O}_{3}$.

Microstructure.- - Light optical photomicrographs of the hot extruded $\mathrm{N}_{2}$-roasted and cryomilled forms of IP $6000 / 1 \mathrm{ZS}$ have been presented in reference 12. The general appearance of these materials was similar and was composed of regions with dense concentrations of second phase particles surrounding regions which appeared to be devoid of particles. The particle-free regions had rectangular to flake-like cross sections and a cigar-like shape parallel to the extrusion axis, where these regions were more numerous and larger after $\mathrm{N}_{2}$-roasting than after cryomilling. In addition some of the larger particle free-regions in the $\mathrm{N}_{2}$-roasted ODS alloy were partially composed of $\gamma^{;}$; this phase was not found in either the base ODS version nor in the cryomilled version of IP 6000/1 Z5. Comparison of the two secondarily processed materials also indicated that the concentration of second phases in the particle-rich areas was greater in $\mathrm{N}_{2}$-roasted ODS alloy than the cryomilled version. Light optical examination of the as-extruded base IP 6000/1 Z5 revealed a structure which is similar to that for the $\mathrm{N}_{2}$-roasted ODS alloy, except the contrast between the particle-rich regions and the particle-deficient regions was lower due to the much lesser AIN + $\mathrm{Al}_{2} \mathrm{O}_{3}$ content (table I).

Transmission electron microscopy of all three forms of IP 6000/1 Z5 was also reported in reference 12 . This work indicated that the basic as-extruded ODS alloy possessed small grains about $1 \mu \mathrm{m}$ in diameter which were slightly elongated in the extrusion direction and second phase particles that generally lie in linear arrays parallel to the elongated grain boundaries. Study of the $\mathrm{N}_{2}$-roasted IP 6000/1 Z5 after hot extrusion indicated that within the particle-rich regions small, irregular shaped submicron grains were decorated by $\sim 150 \mathrm{~nm}$ AlN particles. The particle-rich regions of the cryomilled IP 6000/1 Z5 revealed an equiaxed $\sim 1 \mu \mathrm{m}$ grain structure. While examination of this form revealed a few linear arrays of particles; on a whole, the particles seem to be more evenly distributed in the cryomilled IP 6000/1 Z5 than those in the base alloy. Analysis of the second phases found in all three version of $6000 / 1 \mathrm{ZJ}$ indicated the presence of $\mathrm{Y}_{3} \mathrm{Al}_{5} \mathrm{O}_{12}, \mathrm{AlN}$ and $\mathrm{Al}_{2} \mathrm{O}_{3}$.

Because IP $6000 / 1 \quad[Z 12+Z 13+Z 6 / 1\}$ and IP $6000 / 3 \mathrm{Z15}$ were mechanically alloyed, cryomilled and densified in a similar manner to IP $6000 / 1 \mathrm{Z5}$, the microstructure of hot extruded, cryomilled $\{\mathrm{Z} 12+Z 13+Z 6 / 1\}$ and $Z 15$ should be nearly identical to that of hot extruded, cryomilled Z5.

\section{Elevated temperature Compressive Properties}

Some preliminary $1300 \mathrm{~K}$ compressive test results have been reported in reference 12 on all three forms of IP 6000/1 Z5. All the mechanical property testing results for cryomilled IP 6000/3 and all versions of the two IP 6000/1 alloys are given in the following and compared to one another as well as other NiAl-based alloys. For simplicity the various test results will be presented for each individual alloy/form rather than being grouped by test method.

IP 6000/1 Z5. - The results for multiple constant load compressive tests conducted in an electromechanical test machine at MPI on hot extruded ODS NiAl alloy IP 6000/1 Z5 are given in figures 1 to 5, where parts (a) give the true compressive stress as a function of time, and parts (b) present the true compressive strain as a function of time. Testing was undertaken at each combination of temperature and stress until a steady state or a near steady state deformation rate was obtained. A listing of the temperature-stress-deformation rate data extracted from the multi- 
temperature/stress tests is presented in table A-I(a). The order, running from top to bottom, for each specimen in this list reflects the actual order of testing. In terms of observed mechanical properties, all testing resulted in normal behavior, where the rate of deformation increased as the applied stress and/or temperature was increased.

The true compressive stress-strain curves obtained under multiple constant velocity conditions on hot extruded ODS NiAl alloy IP 6000/1 Z5 are presented in figure 6 for $1200 \mathrm{~K}$ (fig. $6(\mathrm{a})$ ), $1300 \mathrm{~K}$ (fig. $6(\mathrm{~b})$ ) and $1400 \mathrm{~K}$ (fig. 6(c)) testing. The flow strengths and deformation rates for each specimen and imposed constant velocity conditions are listed in table A-I(b). Behavior of the samples tested under multiple constant velocity conditions followed general expectations, where an increase in imposed cross head speed resulted in an increased resistance to deformation. For about half the sets of velocity-temperature conditions, continued flow occurred at a more or less constant stress; in the other cases, strain softening took place after a maximum stress was reached: i.e., the fastest rate of deformation at $1200 \mathrm{~K}$ (fig. 6(a)), $1300 \mathrm{~K}$ (fig. 6(b)) and $1400 \mathrm{~K}$ (fig. 6(c))

Figure 7 presents the flow stress-temperature-strain rate results for hot extruded ODS NiAl alloy IP 6000/1 Z5 at $1200 \mathrm{~K}$ (fig. 7(a)), $1300 \mathrm{~K}$ (fig. 7(b)) and $1400 \mathrm{~K}$ (fig. 7(c)), where data taken from each individual multiple temperature-constant load specimen are identified by their sample number and data from the multiple constant velocity samples are identified by the label "MCV." By visible inspection there does not appear to be any disagreement in the results from different multiple constant load samples nor does there seem to be any discrepancy between the two test methods. This latter contention was tested using linear regression techniques in combination with a dummy variable, where no statistical significant difference could be found between the two procedures. All the flow stress $(\sigma)$ - strain rate $(\dot{\varepsilon})$ data were joined at each temperature $(T)$ and fitted to a simple power law,

$$
\dot{\varepsilon}=A \sigma^{n}
$$

where $\mathrm{A}$ is a constant and $\mathrm{n}$ is a stress exponent, by linear regression techniques. The results of the fits are given by the lines in each part of figures 7 (a) to (c) and the fit parameters, coefficient of determination, $R_{d}{ }^{2}$, and standard deviation for the stress exponent, $\delta_{n}$ are given in table II(a). These fits describe the data reasonably well.

Figure 7(d) presents all the flow stress-strain rate data obtained for hot extruded ODS NiAl alloy IP 6000/1 Z5 between 1200 and $1400 \mathrm{~K}$ and the curves represent the fit obtained utilizing a temperature compensated power law, where

$$
\dot{\varepsilon}=\mathrm{B} \sigma^{\mathrm{n}} \exp \frac{(-\mathrm{Q})}{\mathrm{RT}}
$$

with $B$ being a constant, $Q$ being the activation energy for deformation and $R$ being the universal gas constant.

Values for $B, n, Q$ and standard deviations for the stress exponent and activation energy $\left(\delta_{Q}\right)$ are give in table II(b). Based on visual inspection and the coefficient of determination, a temperature compensated power law can successfully describe the properties of hot extruded IP 6000/1 Z5.

$\underline{\mathrm{N}}_{2}$-roasted Z5. - Five large compression samples of $\mathrm{N}_{2}$-roasted, hot extruded Z5 were tested between 1200 and $1450 \mathrm{~K}$ under multiple constant load conditions in the MPI electromechancial test machine, and the resultant stresstime and creep strain-time curves are presented in figures 8 to 12. A listing of the temperature-stress-deformation rate data extracted from the multi-temperature/stress tests is presented in table A-II(a). Additionally several large compression specimens of $\mathrm{N}_{2}$-roasted, hot extruded $\mathrm{Z5}$ were tested under multiple constant velocity conditions at $1300 \mathrm{~K}$ (fig. 13(a)) and $1400 \mathrm{~K}$ (fig. 13(b)), and the appropriate flow strength and deformation rates are listed in table A-II(b). Examination of the multiple constant load (figs. 8 to 12) and multiple constant velocity (fig. 13) results for hot extruded, $\mathrm{N}_{2}$-roasted $\mathrm{Z5}$ indicates that the behavior is similar to that for the simple hot extruded ODS version of $\mathrm{Z5}$ (figs. 1 to 5 and fig. 6, respectively); however $\mathrm{N}_{2}$-roasting did produce a stronger material.

During preparation of one large $\mathrm{N}_{2}$-roasted, hot extruded $\mathrm{Z} 5$ sample (Z5-N-3) for multiple constant load testing, it fractured into two $9 \mathrm{~mm}$ diameter by $\sim 9 \mathrm{~mm}$ long pieces while a thermocouple was being welded to it. As these two pieces still contained representative $\mathrm{N}_{2}$-roasted material, five smaller compression samples ( $4 \mathrm{~mm}$ diameter by $8 \mathrm{~mm}$ long, length parallel to the extrusion axis) were successfully edm machined from broken halves. All these smaller specimens were tested with the as-edm'ed surface finish, where three of the five were tested under a single constant velocity condition $\left(6.35 \times 10^{-6} \mathrm{~mm} / \mathrm{s}\right)$ at 1200,1300 and $1400 \mathrm{~K}$, respectively and the other two specimens were compression creep tested at 1200 and $1300 \mathrm{~K}$. The stress-strain diagrams from constant velocity compression testing are presented in figure 14(a), while figure 14(b) illustrates the compressive creep curves. The 
temperature-stress-deformation rate data from these two test procedures are given tables A-II(c,d). Comparison of the results in figure 14 to those obtained under different testing conditions and specimen geometry (figs. 8 to 13) indicates that similar behavior was obtained.

The flow stress-temperature-strain rate results for $\mathrm{N}_{2}$-roasted, hot extruded $Z 5$ at 1200,1300 and $1400 \mathrm{~K}$ are presented in figures 15 (a) to (c) respectively, where data taken from (1) each individual multiple constant load specimen is identified by its sample number [" 1 " to " $6 "\}$, (2) multiple constant velocity samples are distinguished by the label "MCV," (3) single value constant velocity specimens are denoted by the label "CV," and finally the compressive creep samples are identified by the label "CL." While some scatter does exist, inspection of these results does not reveal any bias for one test method over another. All the flow stress-strain rate data for each temperature were joined and fitted to a simple exponential law (eq. (3)), since significant curvature was found utilizing power law representations, where $\mathrm{C}$ is a constant by linear regression techniques. The results of the fits are

$$
\dot{\varepsilon}=\mathrm{A} \exp (\mathrm{C} \sigma)
$$

given by the lines in each part of figures 15 (a) to (c) and the fit parameters and standard deviation for the constant $\left(\delta_{\mathrm{C}}\right)$ are given in table $\mathrm{II}(\mathrm{a})$.

Figure 15(d) presents all the flow stress-strain rate data obtained for $\mathrm{N}_{2}$-roasted, hot extruded $\mathrm{Z} 5$ between 1200 and $1450 \mathrm{~K}$, where the curve for the $1200 \mathrm{~K}$ was taken from figure 15 (a) while the curves representing the 1300 to $1450 \mathrm{~K}$ fit were obtained utilizing a temperature compensated exponential law:

$$
\dot{\varepsilon}=\mathrm{B} \exp (\mathrm{C} \sigma) \exp \frac{(-\mathrm{Q})}{\mathrm{RT}}
$$

with $\mathrm{C}$ being a constant. Values for $\mathrm{B}, \mathrm{C}, \mathrm{Q}$ and standard deviations for the stress constant and activation energy $\left(\delta_{\mathrm{i}}\right)$ are given in table $\mathrm{II}(\mathrm{b})$. Based on visual inspection and the coefficient of determination, a temperature compensated exponential law is able to describe the 1300 to $1450 \mathrm{~K}$ data for $\mathrm{N}_{2}$-roasted, hot extruded Z5 reasonably well.

Cryomilled Z5. - True compressive stress-strain diagrams obtained on $5 \mathrm{~mm}$ diameter by $10 \mathrm{~mm}$ tall samples of cryomilled, hot extruded Z5 tested under single constant velocity conditions between 1100 and $1400 \mathrm{~K}$ are given in figures 16 (a) to (d). The vast majority of curves display a steady state like behavior, where continued flow after $\sim 1$ percent strain occurred at a more or less constant stress. Several cryomilled, hot extruded Z5 specimens were also tested under constant load compressive creep conditions, and the resultant curves are illustrated in figure 16(e), and they displayed normal behavior. A listing of the temperature-stress-deformation rate data extracted from the single constant velocity testing and constant load creep testing of cryomilled, hot extruded $\mathrm{Z5}$ is presented in table A-III(a,b), respectively.

Flow stress-strain rate-temperature data for cryomilled, hot extruded $\mathrm{Z5}$ are presented in figure 17 , where the solid symbols represent data taken from constant velocity testing (figs. 16(a) to (d)) and the open symbols signify the creep test (fig. 16(e)) results. The values were fitted to a simple power law (eq. (1)) at each temperature, and the deformation parameters from these fits are given in table II(a). Because the stress exponents for cryomilled, hot extruded Z5 at 1100 and $1200 \mathrm{~K}$ are much higher than those estimated at 1300 and $1400 \mathrm{~K}$ (table II(a)); use of a temperature compensated power law analysis (eq. (2)) was only deemed reasonable for the highest temperature results, where the stress exponents are nearly equal. The results from this latter regression fit are presented in table II(b), where this analysis did not include data from either the $1300 \mathrm{~K}-30 \mathrm{MPa}$ compressive creep test or the $1400 \mathrm{~K}$ constant velocity test at $\sim 2 \times 10^{-7} \mathrm{~s}^{-1}$. With the exception of these two particular points, all the predicted regression curves describe the experimental flow stress-strain rate-temperature values well as can be visualized by the curves in figure 17 which illustrate individual fits (eq. (1)) of the 1100 and $1200 \mathrm{~K}$ results and the combined fit (eq. (2)) of the 1300 and $1400 \mathrm{~K}$ data. These curves also reveal that there is little, if any, difference among the results obtained by either the constant velocity or creep test method; this behavior was confirmed through statistical testing using a dummy variable.

Cryomilled $Z 12+Z 13+Z 6 / 1$. - True compressive stress-strain diagrams for cryomilled, hot extruded $\{Z 12+Z 13+Z 6 / 1\}$ compressed under single constant velocity conditions between 1200 and $1400 \mathrm{~K}$ are given in figures 18(a) to (c), and the temperature-flow stress-deformation rate data extracted from these tests are listed in table A-IV(a). Basically all the stress-strain curves (fig. 18(a) to (c)) illustrate continued flow at an approximately constant stress level after work hardening through the initial $\sim 1$ percent strain. Three constant load compressive 
creep tests were also undertaken on cryomilled, hot extruded $\{Z 12+Z 13+Z 6 / 1\}$ specimens. The strain-time plots for each of these experiments are shown in figure $18(\mathrm{~d})$, and the descriptive test conditions are given in table A-IV(b). The creep curves reveal normal first and second stage behavior.

Figure 19 presents the flow stress-strain rate-temperature data for cryomilled, hot extruded $\{\mathrm{Z} 12+\mathrm{Z} 13+\mathrm{Z} 6 / 1\}$, where the constant velocity test data (figs. 18(a) to (c)) are given as the solid symbols and the creep test (fig. 18(d)) results are characterized by open symbols. In addition to simple power law (eq. (1)) fits at each temperature, a temperature compensated power law (eq. (2)) fit was performed on the 1300 to $1400 \mathrm{~K}$ data. The lines in figure 19 represent the individual fit at $1200 \mathrm{~K}$ and the combined fit of the 1300 and $1400 \mathrm{~K}$ values; all deformation parameters from the regression analyses are given in table II. Based on visual inspection of the data and regression curves in figure 19, it can be seen that the results from constant velocity testing are consistent with those from constant load creep testing. Furthermore the regression coefficients in table II and the regression fits in figure 19 demonstrate that power laws are capable of precisely describing the deformation behavior of cryomilled, hot extruded $\{Z 12+Z 13+Z 6 / 1\}$.

Cryomilled Z15. -True compressive stress-strain diagrams obtained on $5 \mathrm{~mm}$ diameter by $10 \mathrm{~mm}$ tall samples of cryomilled, hot extruded Z15 tested under single constant velocity conditions between 1200 and $1400 \mathrm{~K}$ are given in figures 20 (a) to (c). While the curves do display a steady state like behavior, this regime only occurs after work hardening during the initial $2^{+}$percent strain. As such, the operable range of strain for work hardening in cryomilled, hot extruded Z15 is at least twice that demonstrated by either cryomilled, hot extruded Z5 (figs. 16(b) to (c)) or $\{Z 12+Z 13+Z 6 / 1\}$ (figs. 18 (a) to (c)). Due to this difference, flow stress and strain rate for each constant velocity experiment were evaluated at 3 percent strain \{instead of 1 percent strain\} in order to utilize the full strength potential of cryomilled, hot extruded Z15; a listing of the appropriate temperature-flow strength-strain rate data is given in table A-V(a). Several cryomilled, hot extruded Z15 specimens were also tested under constant load compressive creep conditions, and the resultant curves, which displayed normal behavior, are illustrated in figure 20(d). The numerical data for the constant load creep tests are presented in table A-V(b).

Flow stress-strain rate-temperature data for cryomilled, hot extruded Z15 are shown in figure 21, where the solid symbols represent data taken from constant velocity testing (figs. 20(a) to (c)) and the open symbols signify the creep test results (fig. 20(d)). The values were fitted to simple power (eq. (1)) and exponential (eq. (3)) laws at each temperature. While both laws yielded fits which could describe the results, the exponential stress dependency was slightly better; thus the exponential law parameters are given in table III(a) and the lines characterizing each fit are shown in figure 21 . Although the individual 1200 and $1300 \mathrm{~K}$ fits were very good with very small standard deviations for the stress constant $C$ (table III(a)), it was felt that the stress constants were sufficiently close to one another that a temperature compensated exponential law (eq. (4)) fit could be used to roughly determine an activation energy for deformation. The parameters from the 1200 to $1300 \mathrm{~K}$ fit for cryomilled, hot extruded $\mathrm{Z} 15$ are given in table III(b).

\section{Comparison of $\dot{\varepsilon}-\sigma-T$ behavior}

ODS NiAl.- The most extensive set of data on an as-densified ODS NiAl was collected by Grahle (ref. 5) on IP 6002 (table I) produced with a $2 \mathrm{wt} \%$ addition of yttria during mechanical alloying and densified by Hot Isostatic Pressing (HIP). The resultant $0.9 \mu \mathrm{m}$ grain size alloy was then tested in air at 1200 and $1300 \mathrm{~K}$ under multiple constant stress conditions at MPI. Grahle's results along with those for hot extruded IP 6000/1 Z5 (fig. 7(d)) are shown in figure 22, where the open symbols are the results from Z5 and the solid symbols are from IP 6002. Within the common range of strain rate at each temperature the mechanical properties for both forms of ODS NiAl are very similar. In reality, testing for differences between these two materials through a dummy variable in combination with equation (1) indicated that IP 6002 was slightly stronger than hot extruded Z5 at $1200 \mathrm{~K}$; however at $1300 \mathrm{~K}$ both possessed equivalent strengths. Thus it can be concluded that the present hot extruded IP 6000/1 Z5 has elevated temperature compressive properties which are essentially equivalent to other heats of ODS NiAl.

For completeness the deformation parameters utilizing power law (eq. (1)) and temperature compensated power law (eq. (2)) fits of IP 6002 are give in table II, where the fits involving the $1300 \mathrm{~K}$ results were restricted to strain rates $\leq 10^{-3} \mathrm{~s}^{-1}$.

Three Forms of Z5. - The true compressive flow stress-strain rate-temperature behavior for IP $6000 / 1 \mathrm{Z5}$, which had been simply hot extruded; roasted in nitrogen and then hot extruded; or cryomilled and hot extruded, is compared in figure 23 . Since each part of figure 23 is in a logarithm strain rate-logarithm stress format which 
derives from equations (1) and (2), the behavior of $\mathrm{N}_{2}$-roasted $\mathrm{Z5}$ shows curvature because this material follows exponential laws (eqs. (3) and (4), fig. 15(d)). In terms of strength both cryomilling and $\mathrm{N}_{2}$-roasting have significantly improved the deformation resistance in comparison to the base ODS NiAl alloy at 1200 (fig. 23(a)) 1300 (fig. 23(b)) and $1400 \mathrm{~K}$ (fig. 23(c)), and it is also clear that $\mathrm{N}_{2}$-roasting is more effective than cryomilling at faster strain rates and/or lower temperatures. The advantage of $\mathrm{N}_{2}$-roasting over cryomilling is less certain under prolonged high temperature creep conditions ( 1300 and $1400 \mathrm{~K}-\dot{\varepsilon}<10^{-7} \mathrm{~s}^{-1}$ in figs. 23 (b) and (c)), where the curvature exhibited by $\mathrm{N}_{2}$-roasted suggests weakening at lower stress levels.

Three Lots of Cryomilled ODS NiAl.-Figure 24 presents the true compressive flow stress-strain rate behavior of the three different lots of cryomilled ODS NiAl at 1200 (fig. 24 (a)), 1300 (fig. 24(b)), and $1400 \mathrm{~K}$ (fig. 24(c)). Again due to the power law format in this figure, one alloy (Z15) displays curvature since it appears to more closely follow an exponential stress dependency. While it is possible to go through the results and argue that one particular lot had a strength advantage over the other two lots under some conditions (for example: $\{Z 12+13+Z 6 / 1\}$ is stronger than either $Z 5$ or $Z 15$ at $1200 \mathrm{~K}$ (fig. 24(a)), while $Z 15$ is stronger than either $Z 5$ or $\{Z 12+13+Z 6 / 1\}$ at $1400 \mathrm{~K}$ between $10^{-5}$ and $10^{-6} \mathrm{~s}^{-1}$, figure $24(\mathrm{c})$ ), examination of all the data does not show an overriding superiority for any one of the three cryomilled ODS NiAl's. Therefore for all practical purposes, all three current versions of cryomilled ODS NiAl have about the same compressive elevated temperature creep properties which is, most likely, a simple reflection of their nominally 8 vol \% AlN content (table I).

Cryomilled ODS NiAl versus Cryomilled NiAl.- The primary purpose of this study was to determine if the internal strengthening mechanisms supplied by oxide dispersion strengthening could be superimposed with the grain boundary strengthening effects of cryomilling. Unfortunately, this hope was not realized as can be seen in figure 25 which compares the true compressive flow stress-strain rate properties of the present lots of cryomilled ODS NiAl with $\sim 8 \mathrm{vol} \%$ AlN to those of a cryomilled binary NiAl with a similar amount of AlN (46.5Al-0.1Fe-Ni +8.1 vol \% $\left.\mathrm{AlN}+1.2 \mathrm{vol} \% \mathrm{Al}_{2} \mathrm{O}_{3}+0.5 \mathrm{vol} \% \mathrm{Y}_{2} \mathrm{O}_{3}\right)^{1}$ (ref. 11). While the $1100 \mathrm{~K}$ compressive properties (fig. 25(a)) of cryomilled binary NiAl and Z5 are close to being equal, at 1200 and $1300 \mathrm{~K}$ (figs. 25(b) and (c)) the cryomilled $\mathrm{NiAl}$ is much stronger than the oxide dispersion strengthened $\mathrm{NiAl}$ which had been cryomilled. Therefore, at least, the first attempt to combine dispersion strengthening and cryomilling in NiAl was not successful.

\section{DISCUSSION}

Although this work failed to demonstrate that two independent elevated temperature strengthening mechanisms could be successfully combined in NiAl, a number of secondary aims were achieved. First, it can be seen that the cryomilling process, itself, was reproducible, as the procedures employed in this study resulted in essentially equal AIN contents (table I) and nearly equivalent the flow stress-strain rate-temperature properties for the two lots of ODS NiAl IP 6000/1 (Z5 and $\{Z 12+Z 13+Z 6 / 1\}$, fig. 24). Second, a number of different measurement techniques were employed to determine the flow stress-strain rate-temperature behavior, and all the methods yielded identical properties. For example, four different test methods were used on $\mathrm{N}_{2}$-roasted, hot extruded $\mathrm{Z} 5$ samples, and they all produced an alike flow stress-strain rate-temperature response (figs. 15(a) to (c)). The procedures included two which measured the load in response to an imposed strain rate (single constant velocity testing and multiple constant velocity testing) and two which measured the strain rate in response to imposed load (single stress constant load creep testing and multiple constant load creep testing). Experiments on the other materials also indicated that a variety of test methods would produce equivalent mechanical properties: for example multiple constant load creep and multiple constant velocity testing of hot extruded IP 6000/1 Z5 (figs. 7(a) to (c)), and single constant velocity testing and single constant load creep testing of cryomilled, hot extruded $Z 5,\{Z 12+Z 13+Z 6 / 1\}$ and $Z 15$ (figs. 17,19 and 21 , respectively). Thus, it can be concluded that at least for the current materials, equations (1) to (4) can be manipulated from either side of the relationships.

The experiments also indicate that the amount of dispersoid does not greatly affect the elevated temperature compressive behavior (fig. 24), since both alloys with about 2 vol $\% \mathrm{Y}_{3} \mathrm{Al}_{5} \mathrm{O}_{12}$ (table I) are nearly as equally strong as cryomilled $\mathrm{Z} 15$ which possesses $\sim 6 \mathrm{vol} \% \mathrm{Y}_{3} \mathrm{Al}_{5} \mathrm{O}_{12}$. In terms of matrix chemistry (table I), the almost 3 percent difference in Fe content among $\mathrm{Z} 5$ and $\mathrm{Z} 15$ compared to $\{\mathrm{Z12}+\mathrm{Z13}+\mathrm{Z6} / 1\}$ was surprising. Clearly based on the

\footnotetext{
${ }^{1}$ This alloy was produced by cryomilling prealloyed NiAl powder with an $0.5 \mathrm{wt} \%$ yttria addition which improves the oxidation behavior (ref. 2). Study (ref. 8) of the densified material under a transmission electron microscope did not reveal any evidence that the yttria was dispersed uniformly throughout the $\mathrm{NiAl}$ matrix.
} 
matrix compositions for the base and cryomilled version of Z5, cryomilling introduces Fe into the alloy; however neither cryomilled $Z 5$ nor $Z 15$ have as much $F e$ as cryomilled $\{Z 12+Z 13+Z 6 / 1\}$. The only reasonable explanation lies in the iron content of the original mechanically alloyed ODS NiAl powders, since other work has shown as much as -2 at $\%$ Fe in lots of IP 6000/1 (ref. 1) and IP 6002 (ref. 5) compared to the present heat (Z5) of IP 6000/1 (table I).

Mechanical testing of all three forms of Z5 (fig. 23) indicates that the $\mathrm{N}_{2}$-roasted Z5 is stronger than cryomilled $\mathrm{Z} 5$ which, in tum, is stronger than the base ODS NiAl alloy. Clearly the increased strength after cryomilling is due to the formation of AIN and changes in microstructure (ref. 12). Most probably the additional strength of the $\mathrm{N}_{2}$-roasted Z5 is due to its higher AIN content (table I), since recent work (ref. 14) has demonstrated that the elevated temperature strength of cryomilled $\mathrm{NiAl}$ increases with the square root of the volume fraction of AIN. While the AlN morphology after $\mathrm{N}_{2}$-roasting is not the same as that found after cryomilling ( $150 \mathrm{~nm}$ AlN particles after $\mathrm{N}_{2}$-roasting (ref. 12) compared to $25 \mathrm{~nm}$ particles after cryomilling (ref. 10)), the $2^{+}$factor difference in AlN content between the $\mathrm{N}_{2}$-roasted and cryomilled versions of $\mathrm{Z5}$ (table I) is probably the overriding factor.

While simple $\mathrm{N}_{2}$-roasting appears to give a very strong alloy (fig. 23 ), in reality the strength of $\mathrm{N}_{2}$-roasted Z5 is considerably less than that expected in a properly cryomilled NiAl with 17.5 vol \% AIN. This can be seen in figure 26 which contrasts the $1300 \mathrm{~K}$ flow strength-strain rate behavior of cryomilled NiAl containing from 2.7 to 30.4 vol \% AIN (ref. 14) with the properties of $\mathrm{N}_{2}$-roasted $\mathrm{Z5}$ (fig. 23(b)). Even though this material has 17.6 percent AIN (table I), its strength is clearly inferior to that of a cryomilled binary NiAl with 8.4 vol \% AIN. Part of this discrepancy could be due to a difference in matrix composition, since it has been shown that at $1300 \mathrm{~K}$ Al-deficient NiAl's (Ni-37/40Al) are weaker than NiAl's with Al contents exceeding 44 at \% (refs. 15 and 16). However we believe that the major factor causing relative weakness in $\mathrm{N}_{2}$-roasted $\mathrm{Z5}$ is the large size of AlN $(-150 \mathrm{~nm},($ ref. 12)) in this alloy. Prior work (refs. 1, 10 and 14) has shown that the excellent elevated temperature strength in cryomilled NiAl is due to mantle regions composed of 5 to $50 \mathrm{~nm}$ diameter AlN particles glued together with $\sim 100 \mathrm{~nm} \mathrm{NiAl} \mathrm{grains.} \mathrm{Such} \mathrm{mantle} \mathrm{regions} \mathrm{are} \mathrm{missing} \mathrm{in} \mathrm{the} \mathrm{N}_{2}$-roasted material (ref. 12).

In addition to demonstrating that the strength of $\mathrm{N}_{2}$-roasted $\mathrm{Z5}$ does not follow expectations, figure 26 also indicates that cryomilled Z5 with 8.2 percent AIN is much weaker than expected; in fact cryomilled Z5 is only slightly stronger than a cryomilled binary NiAl with 2.7 vol \% AIN. Again, part of this strength difference could be due to the lower Al level of the matrix for cryomilled $\mathrm{Z5}(42 \mathrm{Al})$ in comparison to the $\mathrm{Ni} \sim 47 \mathrm{Al}$ matrices for the 2.7 to 30.4 vol \% AIN alloys. Secondly, the short term (4 h) cryomilling of the current ODS NiAl materials (Z5, Z15 and $\{Z 12+13+Z 6 / 1\}$ resulted in nitrogen contents ranging from $\sim 1.5$ to $1.9 \mathrm{wt} \%$; such levels are at least twice the amount of nitrogen pickup that was expected based on our previous cryomilling experiments with binary prealloyed NiAl powder in either $01 \mathrm{HD}$ (ref. 17) or $1 \mathrm{~S}$ (ref. 18) attritors. The enhanced nitrogen content could simply be the result of cryomilling a very fine powder \{median as-ODS powder particle size was $<1 \mu \mathrm{m}$, (ref. 6)\} in comparison to much larger (>60 $\mu$ m diameter, (ref. 11)) prealloyed NiAl powders. It is also possible that the as-ODS powder was more reactive during cryomilling and this resulted in a different AIN morphology. If, for example, a more "active" ODS NiAl powder leads to larger than usual AlN sizes, this will result in a weakened material (refs. 2,14 and 19). A more complete understanding of the relative weakness of cryomilled ODS NiAl will require in-depth studies of the transmission level microstructure of the as-extruded material and perhaps the as-cryomilled powder.

\section{SUMMARY OF RESULTS}

A study has been undertaken with $\mathrm{NiAl}$ in an attempt to superimpose oxide dispersion strengthening (ODS) mechanisms with those induced by cryomilling. Three different lots of yttria hardened, mechanically alloyed NiAl powder were cryomilled in liquid nitrogen to introduce AIN particles at the grain boundaries. Chemical analysis revealed that the ODS alloys could be successfully cryomilled, and all three lots contained about $8 \mathrm{vol} \% \mathrm{AlN}$. Following hot extrusion, the materials were compression tested between 1100 and $1400 \mathrm{~K}$, and all three lots displayed similar elevated temperature strength properties. While the cryomilled ODS NiAl alloys were stronger than hot extruded ODS NiAl, cryomilled ODS NiAl was not as strong as a cryomilled NiAl containing a like amount of AIN. Hence the initial attempt to superimpose ODS and cryomilling strengthening mechanisms in NiAl was not successful. Lastly, as an alternative to cryomilling, it was reconfirmed that high temperature roasting of $\mathrm{NiAl}$ powder in nitrogen would also form AlN. Although the $\mathrm{N}_{2}$-roasted $\mathrm{NiAl}$ was relatively strong, its strength appeared to be much less than a cryomilled NiAl with the same amount of AIN. 


\section{APPENDIX}

The following tables document the temperature-flow stress-strain rate data gathered by different testing procedures for analysis of temperature dependent, time dependent strength properties of the various materials. For simplicity the results are grouped by testing procedure.

\section{TABLE A-I-TEMPERATURE-FLOW STRESS STRAIN RATE DATA FOR HOT EXTRUDED ODS NiAl ALLOY IP $6000 / 1$}

(a) Results from multiple temperature-constant load compressive testing

\begin{tabular}{|c|c|c|c|}
\hline $\begin{array}{c}\text { Specimen } \\
\text { D }\end{array}$ & $\begin{array}{c}\text { Temperature, } \\
\text { K }\end{array}$ & $\begin{array}{c}\text { Stress, } \\
\text { MPa }\end{array}$ & $\begin{array}{c}\text { Strain rate, } \\
\text { s }^{-1}\end{array}$ \\
\hline Z5-1 & 1200 & 88.4 & $1.26 \times 10^{-5}$ \\
Z5-1 & 1300 & 14.64 & $6.56 \times 10^{-8}$ \\
Z5-1 & 1300 & 24.14 & $4.50 \times 10^{-7}$ \\
Z5-1 & 1300 & 33.27 & $3.38 \times 10^{-6}$ \\
Z5-1 & 1400 & 9.32 & $1.85 \times 10^{-7}$ \\
Z5-1 & 1400 & 18.19 & $1.83 \times 10^{-6}$ \\
& & & \\
Z5-2 & 1200 & 29.8 & $1.28 \times 10^{-8}$ \\
Z5-2 & 1200 & 58.8 & $2.27 \times 10^{-7}$ \\
Z5-2 & 1400 & 6.1 & $2.23 \times 10^{-8}$ \\
Z5-2 & 1400 & 12.65 & $1.56 \times 10^{-7}$ \\
Z5-2 & 1400 & 27.33 & $2.31 \times 10^{-5}$ \\
& & & \\
Z5-3 & 1300 & 10.3 & $2.06 \times 10^{-8}$ \\
Z5-3 & 1300 & 19.79 & $1.13 \times 10^{-7}$ \\
Z5-3 & 1400 & 12.91 & $2.65 \times 10^{-7}$ \\
Z5-3 & 1400 & 22.49 & $6.37 \times 10^{-6}$ \\
& & & \\
Z5-4 & 1200 & 74.58 & $2.83 \times 10^{-7}$ \\
Z5-4 & 1200 & 99.25 & $1.27 \times 10^{-5}$ \\
Z5-4 & 1300 & 26.98 & $3.00 \times 10^{-7}$ \\
Z5-4 & 1300 & 38.4 & $4.39 \times 10^{-6}$ \\
Z5-4 & 1300 & 54.92 & $3.76 \times 10^{-5}$ \\
& & & \\
Z5-5 & 1200 & 45.46 & $1.06 \times 10^{-7}$ \\
Z5-5 & 1200 & 78.34 & $2.93 \times 10^{-6}$ \\
Z5-5 & 1400 & 6.7 & $1.15 \times 10^{-7}$ \\
Z5-5 & 1400 & 12.17 & $4.42 \times 10^{-7}$ \\
\hline
\end{tabular}

(b) Results from multiple constant velocity compressive testing

\begin{tabular}{|c|c|r|c|}
\hline $\begin{array}{c}\text { Specimen } \\
\text { ID }\end{array}$ & $\begin{array}{c}\text { Temperature, } \\
\text { K }\end{array}$ & $\begin{array}{c}\text { Stress, } \\
\text { MPa }\end{array}$ & $\begin{array}{c}\text { Strain rate, } \\
\mathrm{s}^{-1}\end{array}$ \\
\hline $\mathbf{Z 5 - 8}$ & 1200 & 70.4 & $7.26 \times 10^{-7}$ \\
$\mathbf{Z 5 - 8}$ & 1200 & 101.2 & $7.43 \times 10^{-6}$ \\
$\mathbf{Z 5 - 8}$ & 1200 & 139.4 & $7.75 \times 10^{-5}$ \\
$\mathbf{Z 5 - 8}$ & 1200 & 195.1 & $8.00 \times 10^{-4}$ \\
& & & \\
$\mathbf{Z 5 - 6}$ & 1300 & 34.1 & $1.21 \times 10^{-6}$ \\
$\mathbf{Z 5 - 6}$ & 1300 & 51.9 & $1.28 \times 10^{-5}$ \\
$\mathbf{Z 5 - 6}$ & 1300 & 73.4 & $1.36 \times 10^{-4}$ \\
$\mathbf{Z 5 - 6}$ & 1300 & 114.3 & $1.45 \times 10^{-3}$ \\
& & & \\
$\mathbf{Z 5 - 7}$ & 1400 & 17.8 & $1.22 \times 10^{-6}$ \\
$\mathbf{Z 5 - 7}$ & 1400 & 27.8 & $1.29 \times 10^{-5}$ \\
$\mathbf{Z 5 - 7}$ & 1400 & 38.4 & $1.39 \times 10^{-4}$ \\
$\mathbf{Z 5 - 7}$ & 1400 & 59.2 & $1.45 \times 10^{-3}$ \\
\hline
\end{tabular}

\section{TABLE A-II-TEMPERATURE-FLOW STRESS-STRAIN RATE DATA FOR $\mathrm{N}_{2}$-ROASTED, HOT EXTRUDED Z5}

(a) Results from multiple temperature-constant load compressive testing

\begin{tabular}{|c|c|c|c|}
\hline $\begin{array}{c}\text { Specimen } \\
\text { ID }\end{array}$ & $\begin{array}{c}\text { Temperature, } \\
\text { K }\end{array}$ & $\begin{array}{c}\text { Stress, } \\
\text { MPa }\end{array}$ & $\begin{array}{c}\text { Strain rate, } \\
\mathrm{s}^{-1}\end{array}$ \\
\hline Z5-N-1 & 1300 & 49.71 & $2.81 \times 10^{-7}$ \\
Z5-N-1 & 1300 & 73.92 & $6.55 \times 10^{-7}$ \\
Z5-N-1 & 1300 & 99.12 & $2.14 \times 10^{-6}$ \\
Z5-N-1 & 1300 & 147.57 & $9.95 \times 10^{-6}$ \\
& & & \\
Z5-N-2 & 1300 & 34.82 & $1.63 \times 10^{-8}$ \\
Z5-N-2 & 1300 & 49.6 & $3.23 \times 10^{-8}$ \\
Z5-N-2 & 1300 & 73.65 & $3.08 \times 10^{-7}$ \\
Z5-N-2 & 1300 & 149.97 & $3.50 \times 10^{-5}$ \\
& & & \\
Z5-N-4 & 1400 & 34.46 & $5.87 \times 10^{-7}$ \\
Z5-N-4 & 1400 & 24.96 & $1.09 \times 10^{-7}$ \\
Z5-N-4 & 1400 & 48.79 & $6.29 \times 10^{-7}$ \\
Z5-N-4 & 1400 & 72.03 & $2.93 \times 10^{-6}$ \\
Z5-N-4 & 1400 & 94.62 & $1.05 \times 10^{-5}$ \\
Z5-N-4 & 1450 & 14.59 & $2.43 \times 10^{-7}$ \\
& & & \\
Z5-N-5 & 1200 & 100.07 & $6.52 \times 10^{-10}$ \\
Z5-N-5 & 1200 & 173.73 & $1.59 \times 10^{-8}$ \\
& & & \\
Z5-N-6 & 1400 & 15.1 & $2.55 \times 10^{-8}$ \\
Z5-N-6 & 1400 & 30.32 & $7.46 \times 10^{-8}$ \\
Z5-N-6 & 1400 & 39.67 & $1.08 \times 10^{-7}$ \\
Z5-N-6 & 1400 & 77.62 & $9.90 \times 10^{-7}$ \\
\hline
\end{tabular}

(b) Results from multiple constant velocity compressive testing

\begin{tabular}{|c|c|c|c|}
\hline $\begin{array}{c}\text { Specimen } \\
\text { D }\end{array}$ & $\begin{array}{c}\text { Temperature, } \\
\mathrm{K}\end{array}$ & $\begin{array}{c}\text { Stress, } \\
\mathrm{MPa}\end{array}$ & $\begin{array}{c}\text { Strain rate, } \\
\mathrm{s}^{-1}\end{array}$ \\
\hline Z5-N-7 & 1300 & 100.5 & $7.58 \times 10^{-7}$ \\
Z5-N-7 & 1300 & 148.4 & $7.74 \times 10^{-6}$ \\
Z5-N-7 & 1300 & 170 & $7.93 \times 10^{-5}$ \\
Z5-N-7 & 1300 & 193.4 & $8.1 \times 10^{-4}$ \\
& & & \\
Z5-N-8 & 1400 & 57.9 & $6.36 \times 10^{-7}$ \\
Z5-N-8 & 1400 & 96.2 & $6.48 \times 10^{-6}$ \\
Z5-N-8 & 1400 & 123.8 & $6.67 \times 10^{-5}$ \\
Z5-N-8 & 1400 & 138.5 & $6.8 \times 10^{-4}$ \\
\hline
\end{tabular}

(c) Results from single constant velocity compressive testing

\begin{tabular}{|c|c|c|}
\hline $\begin{array}{c}\text { Temperature, } \\
\mathrm{K}\end{array}$ & $\begin{array}{c}\text { Stress, } \\
\mathrm{MPa}\end{array}$ & $\begin{array}{c}\text { Strain rate, } \\
\mathrm{s}^{-1}\end{array}$ \\
\hline 1200 & 199.7 & $7.27 \times 10^{-7}$ \\
1300 & 106 & $7.03 \times 10^{-7}$ \\
1400 & 51.7 & $7.11 \times 10^{-7}$ \\
\hline
\end{tabular}

(d) Results from constant load compressive creep testing

\begin{tabular}{|c|c|c|}
\hline $\begin{array}{c}\text { Temperature, } \\
\mathbf{K}\end{array}$ & $\begin{array}{c}\text { Stress, } \\
\mathrm{MPa}\end{array}$ & $\begin{array}{c}\text { Strain rate, } \\
\mathrm{s}^{-1}\end{array}$ \\
\hline 1200 & 146.6 & $1.27 \times 10^{-8}$ \\
1300 & 34.8 & $3.31 \times 10^{-9}$ \\
1300 & 49.6 & $1.02 \times 10^{-8}$ \\
\hline
\end{tabular}


TABLE A-III-TEMPERATUREFLOW STRESS-STRAIN RATE

DATA FOR CRYOMILLED, HOT EXTRUDED Z5

(a) Results from single constant velocity compressive testing

\begin{tabular}{|c|c|c|}
\hline $\begin{array}{c}\text { Temperature, } \\
\mathrm{K}\end{array}$ & $\begin{array}{c}\text { Stress, } \\
\mathrm{MPa}\end{array}$ & $\begin{array}{c}\text { Strain rate, } \\
\mathrm{s}^{-1}\end{array}$ \\
\hline 1100 & 219.4 & $9.66 \times 10^{-8}$ \\
1100 & 244.0 & $1.35 \times 10^{-6}$ \\
1100 & 287.0 & $2.07 \times 10^{-5}$ \\
1100 & 330.8 & $2.18 \times 10^{-4}$ \\
& & \\
1200 & 130.2 & $1.84 \times 10^{-7}$ \\
1200 & 152.9 & $1.35 \times 10^{-6}$ \\
1200 & 189.3 & $2.20 \times 10^{-5}$ \\
1200 & 216.8 & $2.28 \times 10^{-4}$ \\
1200 & 297.8 & $2.25 \times 10^{-3}$ \\
& & \\
1300 & 62.7 & $1.94 \times 10^{-7}$ \\
1300 & 80.9 & $1.15 \times 10^{-6}$ \\
1300 & 113.0 & $2.26 \times 10^{-5}$ \\
1300 & 142.5 & $2.30 \times 10^{-4}$ \\
1300 & 172.6 & $2.15 \times 10^{-3}$ \\
& & \\
1400 & 25.6 & $1.85 \times 10^{-7}$ \\
1400 & 42.2 & $1.30 \times 10^{-6}$ \\
1400 & 52.5 & $3.72 \times 10^{-6}$ \\
1400 & 67.7 & $2.13 \times 10^{-5}$ \\
1400 & 88.5 & $2.28 \times 10^{-4}$ \\
1400 & 108.2 & $2.10 \times 10^{-4}$ \\
\hline & &
\end{tabular}

(b) Results from constant load compressive creep testing

\begin{tabular}{|c|c|c|}
\hline $\begin{array}{c}\text { Temperature, } \\
\text { K }\end{array}$ & $\begin{array}{c}\text { Stress, } \\
\mathrm{MPa}\end{array}$ & $\begin{array}{c}\text { Strain rate, } \\
\mathrm{s}-1\end{array}$ \\
\hline 1200 & 98.1 & $8.76 \times 10^{-9}$ \\
1300 & 49.8 & $3.37 \times 10^{-8}$ \\
1300 & 47.7 & $1.51 \times 10^{-8}$ \\
1300 & 26.7 & $5.26 \times 10^{-9}$ \\
1400 & 53.9 & $5.14 \times 10^{-6}$ \\
1400 & 47.0 & $9.14 \times 10^{-7}$ \\
1400 & 33.0 & $8.55 \times 10^{-8}$ \\
\hline
\end{tabular}

TABLE A-IV.-TEMPERATURE FLOW STRESS-STRAIN RATE DATA FOR CR YOMILLED, HOT EXTRUDED $\{Z 12+Z 13+Z 6 / 1\}$

(a) Results from single constant velocity compressive testing

\begin{tabular}{|c|c|c|}
\hline $\begin{array}{c}\text { Temperature, } \\
\mathrm{K}\end{array}$ & $\begin{array}{c}\text { Stress, } \\
\mathrm{MPa}\end{array}$ & $\begin{array}{c}\text { Strain rate, } \\
\mathrm{s}^{-1}\end{array}$ \\
\hline 1200 & 253.1 & $2.31 \times 10^{-4}$ \\
1200 & 212.2 & $2.33 \times 10^{-5}$ \\
1200 & 179.7 & $1.65 \times 10^{-6}$ \\
1200 & 142.3 & $2.08 \times 10^{-7}$ \\
& & \\
1300 & 148.4 & $2.08 \times 10^{-4}$ \\
1300 & 128.9 & $2.15 \times 10^{-5}$ \\
1300 & 94.5 & $1.61 \times 10^{-6}$ \\
1300 & 60.9 & $2.08 \times 10^{-7}$ \\
& & \\
1400 & 87.6 & $1.97 \times 10^{-4}$ \\
1400 & 61.6 & $1.71 \times 10^{-5}$ \\
1400 & 47.3 & $1.56 \times 10^{-6}$ \\
\hline
\end{tabular}

(b) Results from constant load compressive creep testing

\begin{tabular}{|c|c|c|}
\hline $\begin{array}{c}\text { Temperature, } \\
\text { K }\end{array}$ & $\begin{array}{c}\text { Stress, } \\
\mathrm{MPa}\end{array}$ & $\begin{array}{c}\text { Strain rate, } \\
\mathrm{s}^{-1}\end{array}$ \\
\hline 1200 & 121.4 & $2.53 \times 10^{-8}$ \\
1300 & 48.3 & $2.40 \times 10^{-8}$ \\
1400 & 29.0 & $2.52 \times 10^{-8}$ \\
\hline
\end{tabular}

TABLE A-V.-TEMPERATURE FLOW STRESS-STRAIN RATE DATA FOR CRYOMILLED, HOT EXTRUDED ZIS

(a) Results from single constant velocity compressive testing

\begin{tabular}{|c|c|c|}
\hline $\begin{array}{c}\text { Temperature, } \\
\text { K }\end{array}$ & $\begin{array}{c}\text { Stress, } \\
\mathrm{MPa}\end{array}$ & $\begin{array}{c}\text { Strain rate, } \\
\mathrm{s}^{-1}\end{array}$ \\
\hline 1200 & 241.7 & $2.28 \times 10^{-4}$ \\
1200 & 196.3 & $1.86 \times 10^{-5}$ \\
1200 & 166.4 & $1.69 \times 10^{-6}$ \\
1200 & 131.1 & $1.84 \times 10^{-7}$ \\
& & \\
1300 & 150.1 & $2.07 \times 10^{-4}$ \\
1300 & 126.7 & $2.06 \times 10^{-5}$ \\
1300 & 95.8 & $1.50 \times 10^{-6}$ \\
1300 & 72.4 & $1.81 \times 10^{-7}$ \\
& & \\
1400 & 90.2 & $2.13 \times 10^{-4}$ \\
1400 & 75.9 & $1.80 \times 10^{-5}$ \\
1400 & 56.1 & $1.47 \times 10^{-6}$ \\
1400 & 38.0 & $2.63 \times 10^{-7}$ \\
\hline
\end{tabular}

(b) Results from constant load compressive creep testing

\begin{tabular}{|c|c|c|}
\hline $\begin{array}{c}\text { Temperature, } \\
\mathrm{K}\end{array}$ & $\begin{array}{c}\text { Stress, } \\
\mathrm{MPa}\end{array}$ & $\begin{array}{c}\text { Strain rate, } \\
\mathrm{s}^{-1}\end{array}$ \\
\hline 1200 & 98.2 & $1.03 \times 10^{-8}$ \\
1200 & 96.4 & $1.15 \times 10^{-8}$ \\
1300 & 48.1 & $2.08 \times 10^{-8}$ \\
1400 & 28.6 & $4.20 \times 10^{-8}$ \\
\hline
\end{tabular}




\section{REFERENCES}

1. E. Arzt and P. Grahle, High-Temperature Ordered Intermetallic Alloys VI, Vol. 364, Part 1; (eds. J.A. Horton, I. Baker, S. Hanada, R.D. Noebe and D.S. Schwartz), Materials Research Society, Pittsburgh, PA, 1995, pp. 525-36.

2. J.D. Whittenberger, Structural Intermetallics, (eds. R. Darolia, J.J. Lewandowski, C.T. Liu, P.L. Martin, D.B. Miracle and M.V. Nathal) TMS, Warrendale, PA 1993, pp. 819-28.

3. K. Zöltzer, K. Proceedings of the $13^{\text {th }}$ International Plansee Seminar '93, (eds. H. Bildstein and R. Eck) Vol. 3, Ruette, Austria, 1993, pp. 528-536.

4. E. Arzt, E.Göhring and P. Grahle, High-Temperature Ordered Intermetallic Alloys V, Vol. 288, (eds. I. Baker, R. Darolia, J.D. Whittenberger and M.H. Yoo), Materials Research Society, Pittsburgh, PA, 1993, pp. 861-66.

5. P. Grahle, "Mechanisches Legieren, Gefüge und Kriechverhalten dispersiongehärtet NiAl-Werkstoffe" PhD. Thesis University of Stuttgart and Max-Planck Institut für Metallforschung, Stuttgart, 1995.

6. P. Grahle and E. Arzt, Acta Mater. 45 (1997) pp. 201-211.

7. J.D. Whittenberger, E. Arzt, and M.J. Luton, M.J, J. Mat. Res 5 (1990) pp. 271-277.

8. B.J.M. Aikin, R.M. Dickerson, D.T. Jayne, S. Farmer and J.D. Whittenberger. Scripta Metall. et Mater. 30 (1994) pp. 119-22.

9. A. Garg, J.D. Whittenberger, and B.J.M. Aikin, Intermetallic Composites III, Vol. 350, (eds. J.A. Graves, R.R. Bowman, and J.J. Lewandowski), Materials Research Society, Pittsburgh, PA, 1994, pp. 231-2236.

10. Anita Garg, J.D. Whittenberger, Michael.J. Luton. High-Temperature Ordered Intermetallic Alloys VII, Vol. 460, (eds. C.C. Koch, C.T. Liu, N.S. Stoloff and A. Wanner), Materials Research Society, Pittsburgh, PA, 1997, pp. 413-418.

11. J.D. Whittenberger and M.J. Luton, J. Mater. Res. 10 (1995) pp. 1171-1186.

12. J.D. Whittenberger , Peter Grahle, Eduard Arzt, Robert Behr, Klaus Zöltzer and Mohan Hebsur. HighTemperature Ordered Intermetallic Alloys VII, Vol. 460, (eds. C.C. Koch, C.T. Liu, N.S. Stoloff and A. Wanner), Materials Research Society, Pittsburgh, PA, 1997, pp. 487-492.

13. J.D. Whittenberger, B.C. Buzek and G. Wirth, J. Mat. Sci. 21 (1986) pp. 923-30.

14. Mohan G. Hebsur, J.D. Whittenberger, and A. Garg. Structural Intermetallics 1997 (ed. M.V. Nathal, R. Darolia, C.T. Liu, P.L. Martin, D.B. Miracle, R. Wagner and M. Yamaguchi) TMS, Warrendale, PA, 1997 pp. 621-630.

15. J.D. Whittenberger, K.S. Kumar and S. K. Mannan. J. Mat. Sci. 26 (1991) pp. 2015-22.

16. J.D. Whittenberger. J. Mat. Sci. 22 (1987) pp. 394-402.

17. M.G. Hebsur, J.D. Whittenberger, C.E. Lowell. NiAl-Base Composites Containing High Volume Fraction of AlN for Advanced Engines. U.S. Patent Number 5,635,654; June 3, 1997.

18. M.G. Hebsur, unpublished research, 1997.

19. J.D. Whittenberger, A. Garg, M.G. Hebsur, submitted for publication.

TABLE I.-APPROXIMATE MATRIX COMPOSITIONS AND VOLUME FRACTIONS OF SECOND PHASES

\begin{tabular}{|c|c|c|c|c|c|c|}
\hline \multirow[t]{3}{*}{ Alloy } & \multicolumn{3}{|c|}{ Matrix } & \multicolumn{3}{|c|}{ Second phases } \\
\hline & $\overline{A l}$ & $\mathrm{Fe}$ & $\overline{\mathrm{Ni}}$ & $\mathrm{Y}_{3} \mathrm{Al}_{5} \mathrm{O}_{12}$ & AlN & $\mathrm{Al}_{2} \mathrm{O}_{3}$ \\
\hline & \multicolumn{3}{|c|}{ Atom, percent } & \multicolumn{3}{|c|}{ Volume percent } \\
\hline \multicolumn{7}{|c|}{$\mathrm{ZS}^{\mathrm{a}}$} \\
\hline Base & 45.0 & $\overline{0.6}$ & 54.2 & 2.2 & 0.9 & 3.0 \\
\hline $\mathrm{N}_{2}$-roasted & 38.3 & 0.7 & 60.9 & 2,2 & 17.6 & 2.4 \\
\hline Cryomilled & 41.9 & 2.3 & 55.5 & 2.1 & 8.2 & 3.8 \\
\hline $\multicolumn{7}{|c|}{\mathrm{Z} 12+\mathrm{Z} 13+\mathrm{Z} 6 / 1}^{2}$ \\
\hline Cryomilled & 44.2 & 4.9 & 50.3 & 2.4 & 8.6 & 25 \\
\hline \multicolumn{7}{|c|}{$\mathrm{Z15}^{\mathrm{a}}$} \\
\hline Cryomilled & 42.7 & 1.9 & 54.5 & 6.9 & 8.0 & 0.7 \\
\hline \multicolumn{7}{|c|}{ IP 6002 (ref. 5) } \\
\hline Hip'ed & 46.7 & 2.0 & 51.3 & 4.6 & 0.2 & $-\cdots$ \\
\hline
\end{tabular}

${ }^{a}$ Matrix also contains small amounts $(<0.1$ at \%) of C, $\mathrm{Cr}, \mathrm{Co}$, and $\mathrm{Mn}$. 
TABLE II.-POWER LAW DESCRIPTIONS OF THE FLOW STRESS-STRAIN RATES FOR SEVERAL FORMS OF IP 6000/1 AND IP 6000/3

(a) Constant temperature power law fits

\begin{tabular}{|l|c|c|c|r|r|}
\hline \multicolumn{1}{|c|}{ ID } & $\begin{array}{c}\text { Temperature, } \\
\mathrm{K}\end{array}$ & $\begin{array}{c}\mathrm{A}, \\
\mathrm{s}^{-1}\end{array}$ & $\mathrm{n}$ & $\mathrm{R}_{\mathrm{d}}{ }^{2}$ & $\delta_{\mathrm{n}}$ \\
\hline IP 6000/1 Z5 & 1200 & $1.25 \times 10^{-17}$ & 5.98 & 0.975 & 0.32 \\
& 1300 & $1.15 \times 10^{-15}$ & 4.80 & .969 & .27 \\
& 1400 & $4.27 \times 10^{-12}$ & 4.61 & .949 & .32 \\
\hline Cryomilled & 1100 & $1.09 \times 10^{-30}$ & 18.4 & 0.999 & 1.13 \\
Z5 & 1200 & $3.09 \times 10^{-32}$ & 11.7 & .989 & .62 \\
& 1300 & $3.20 \times 10^{-23}$ & 8.77 & .994 & .31 \\
& 1400 & $3.33 \times 10^{-20}$ & 8.18 & .985 & .41 \\
\hline Cryomilled & 1200 & $7.75 \times 10^{-34}$ & 12.2 & 0.993 & 0.62 \\
\{Z12+Z13+Z6/1\} & 1300 & $8.38 \times 10^{-21}$ & 7.40 & .970 & .75 \\
& 1400 & $2.92 \times 10^{-20}$ & 8.19 & .998 & .29 \\
\hline IP 6002 (ref. 5) & 1200 & $1.22 \times 10^{-18}$ & 6.32 & 0.998 & 0.18 \\
& 1300 & $7.45 \times 10^{-17}$ & 6.73 & .985 & .41 \\
\hline
\end{tabular}

(b) Temperature compensated power law fits

\begin{tabular}{|l|c|c|c|c|c|c|c|}
\hline \multicolumn{1}{|c|}{ ID } & $\begin{array}{c}\text { Temperature } \\
\text { regime, } \\
\mathrm{K}\end{array}$ & $\begin{array}{c}\mathrm{B} \\
\mathrm{s}^{-1}\end{array}$ & $\mathrm{n}$ & $\begin{array}{c}\mathrm{Q}, \\
\mathrm{kJ} / \mathrm{mol}\end{array}$ & $\mathrm{R}_{\mathrm{d}}{ }^{2}$ & $\delta_{\mathrm{n}}$ & $\begin{array}{c}\delta_{\mathrm{Q}^{\prime}} \\
\mathrm{kJ} / \mathrm{mol}\end{array}$ \\
\hline IP 6000/1 Z5 & 1200 to 1400 & $1.45 \times 10^{7}$ & 4.96 & 507.5 & 0.953 & 0.19 & 28.7 \\
\hline Cryomilled Z5 & 1300 to 1400 & $9.21 \times 10^{4}$ & 8.53 & 671.9 & 0.989 & 0.26 & 36.2 \\
\hline $\begin{array}{l}\text { Cryomilled } \\
\{Z 12+Z 13+Z 6 / 1\}\end{array}$ & 1300 to 1400 & $9.65 \times 10^{6}$ & 7.73 & 689.4 & 0.980 & 0.45 & 67.7 \\
\hline IP 6002 (ref. 5) & 1200 to 1300 & $7.49 \times 10^{14}$ & 6.62 & 767.0 & 0.988 & 0.28 & 42.6 \\
\hline
\end{tabular}

TABLE III.-EXPONENTIAL LAW DESCRIPTIONS OF THE FLOW STRESS-STRAIN RATES FOR $\mathrm{N}_{2}$-ROASTED, HOT EXTRUDED Z5 AND CRYOMILLED, HOT EXTRUDED Z15

(a) Constant temperature exponential law fits

\begin{tabular}{|c|c|c|r|r|r|}
\hline ID & Temperature, & $\mathrm{A}$ & $\mathrm{C}$ & $\mathrm{R}_{\mathrm{d}}{ }^{2}$ & $\delta_{\mathrm{C}}$ \\
\hline $\mathrm{N}_{2}$-roasted Z5 & \multicolumn{1}{|c|}{$\mathrm{s}^{-1}$} & & & \\
& 1300 & $8.58 \times 10^{-13}$ & 0.064 & 0.900 & 0.015 \\
& 1400 & $9.93 \times 10^{-10}$ & .067 & .947 & .005 \\
& 1400 & $9.31 \times 10^{-9}$ & .074 & .961 & .005 \\
\hline Cryomilled Z15 & 1200 & $1.44 \times 10^{-11}$ & 0.070 & 0.995 & 0.002 \\
& 1300 & $2.77 \times 10^{-10}$ & .090 & .999 & .001 \\
& 1400 & $1.17 \times 10^{-9}$ & .131 & .990 & .007 \\
\hline
\end{tabular}

(b) Temperature compensated exponential law fits

\begin{tabular}{|c|c|c|c|c|c|c|c|}
\hline ID & $\begin{array}{c}\text { Temperature } \\
\text { regime, } \\
\mathrm{K}\end{array}$ & $\begin{array}{c}\mathrm{B}, \\
\mathrm{s}^{-1}\end{array}$ & $\mathrm{C}$ & $\begin{array}{c}\mathrm{Q}, \\
\mathrm{kJ} / \mathrm{mol}\end{array}$ & $\mathrm{R}_{\mathrm{d}}{ }^{2}$ & $\delta_{\mathrm{n}}$ & $\begin{array}{c}\delta_{\mathrm{Q}}, \\
\mathbf{k J} / \mathrm{m} \\
\mathrm{ol}\end{array}$ \\
\hline $\mathbf{N}_{2}$-roasted Z5 & 1300 to 1450 & $1.90 \times 10^{8}$ & 0.069 & 432.4 & 0.95 & 0.003 & 44.9 \\
\hline Cryomilled Z15 & 1200 to 1300 & $1.50 \times 10^{18}$ & 0.076 & 675.4 & 0.985 & 0.003 & 48.9 \\
\hline
\end{tabular}



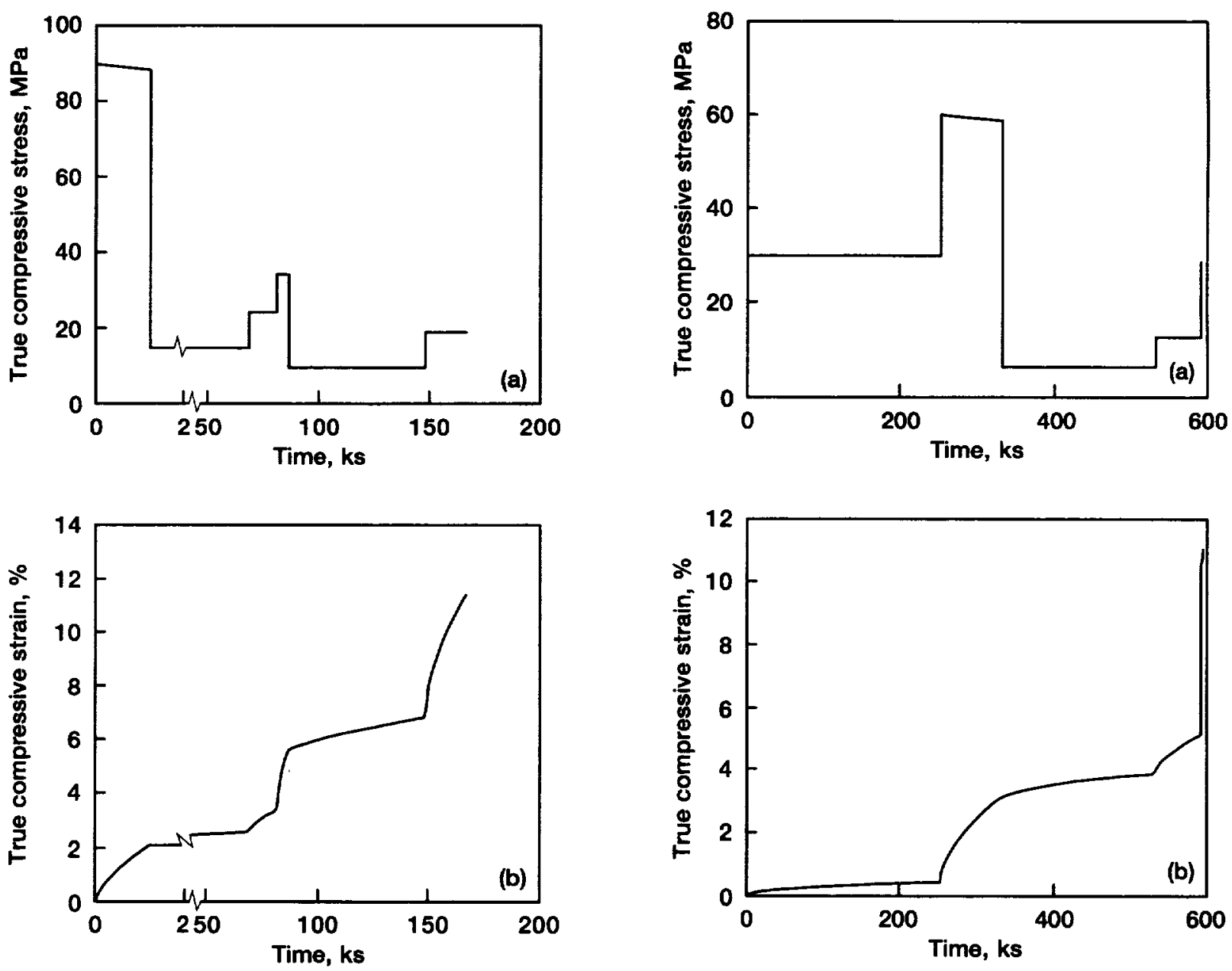

Figure 1.-True compressive stress (a) and true compressive strain (b) as a function of time from multiple temperature-constant load compressive testing of hot extruded ODS NiAl alloy IP 6000/1: specimen Z 5-1. The test temperature, flow stress and deformation rate for each portion of the experiment are given in Table A-I (a).

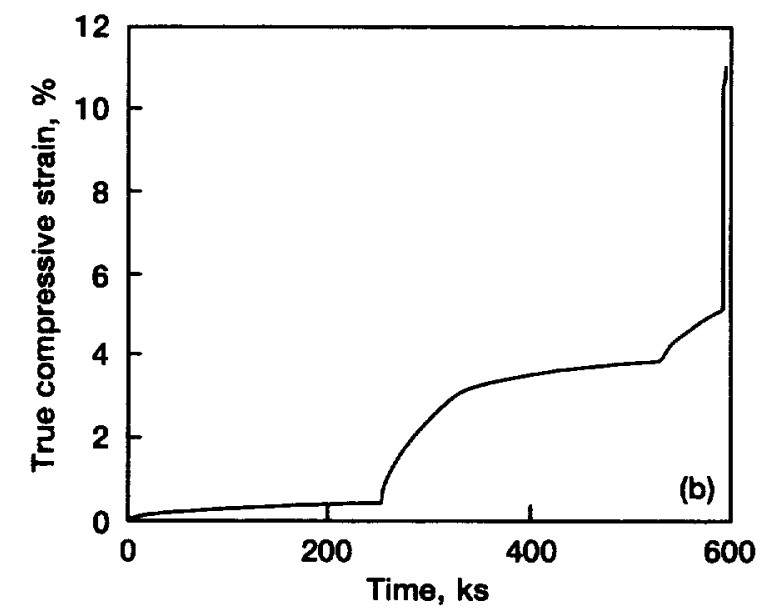

Figure 2.-True compressive stress (a) and true compressive strain (b) as a function of time from multiple temperature-constant load compressive testing of hot extruded ODS NiAl alloy IP 6000/1: specimen Z 5-2. The test temperature, flow stress and deformation rate for each portion of the experiment are given in Table A-I (a). 

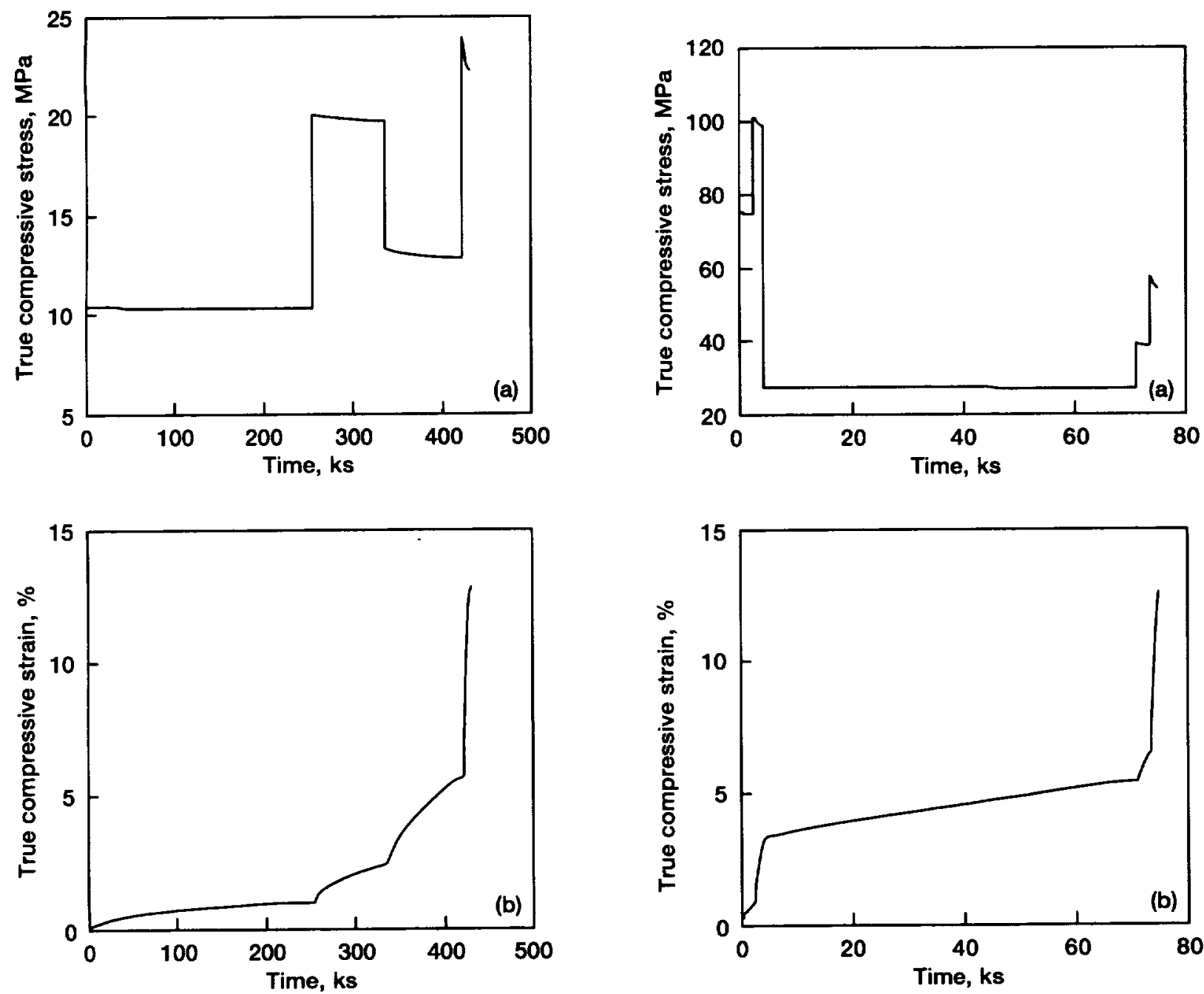

Figure 3.-True compressive stress (a) and true compressive strain (b) as a function of time from multiple temperature-constant load compressive testing of hot extruded ODS NiAl alloy IP 6000/1: specimen Z 5-3. The test temperature, flow stress and deformation rate for each portion of the experiment are given in Table A-I (a). 

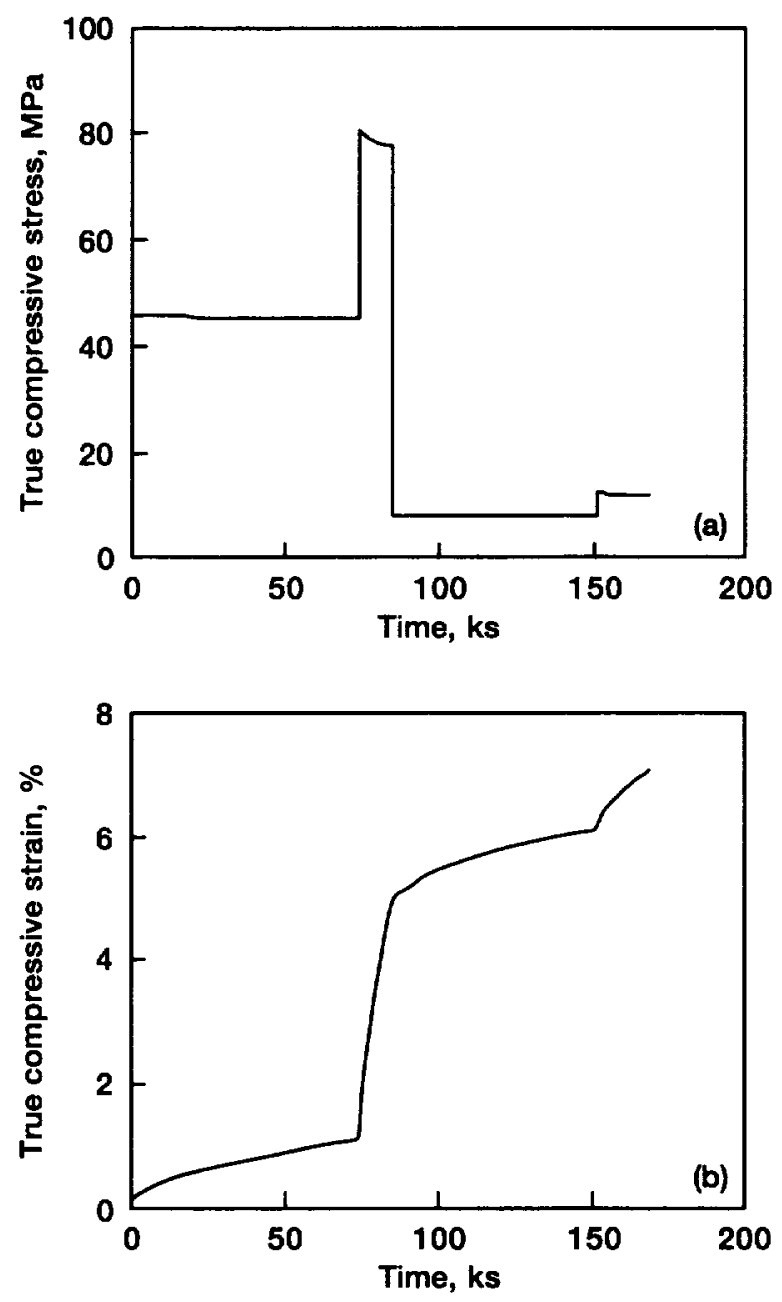

Figure 5.-True compressive stress (a) and true compressive strain (b) as a function of time from multiple temperature-constant load compressive testing of hot extruded ODS NiAl alloy IP 6000/1: specimen Z 5-5. The test temperature, flow stress and deformation rate for each portion of the experiment are given in Table A-I (a). 

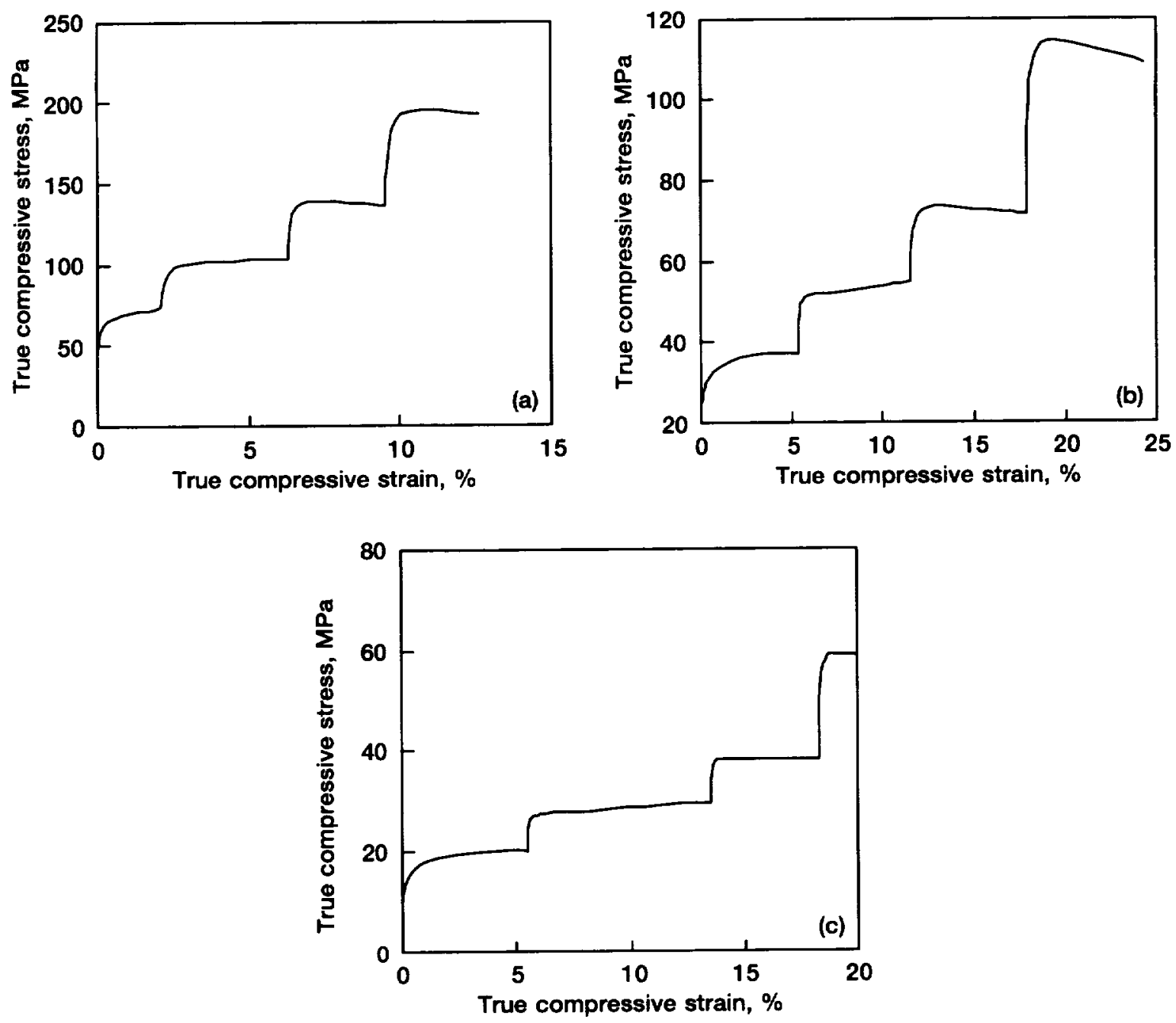

Figure 6.-True compressive stress-strain curves from multiple constant velocity testing of hot extruded ODS NiAl alloy IP 6000/1 Z 5 in an universal test machine. (a) $1200 \mathrm{~K}$ where the crosshead velocities were increased in order from $1.27 x^{-5}, 1.27 x^{-4}, 1.27 x^{-3}$ to $1.27 x^{-2} \mathrm{~mm} / \mathrm{s}$; (b) $1300 \mathrm{~K}$ and (c) $1400 \mathrm{~K}$ where the crosshead velocities were increased in order from $2.12 x^{-5}, 2.12 x^{-4}, 2.12 x^{-3}$ to $2.12 x^{-2} \mathrm{~mm} / \mathrm{s}$. The test temperature, flow stress and deformation rate for each portion of the experiment are listed in Table A-I (b). 

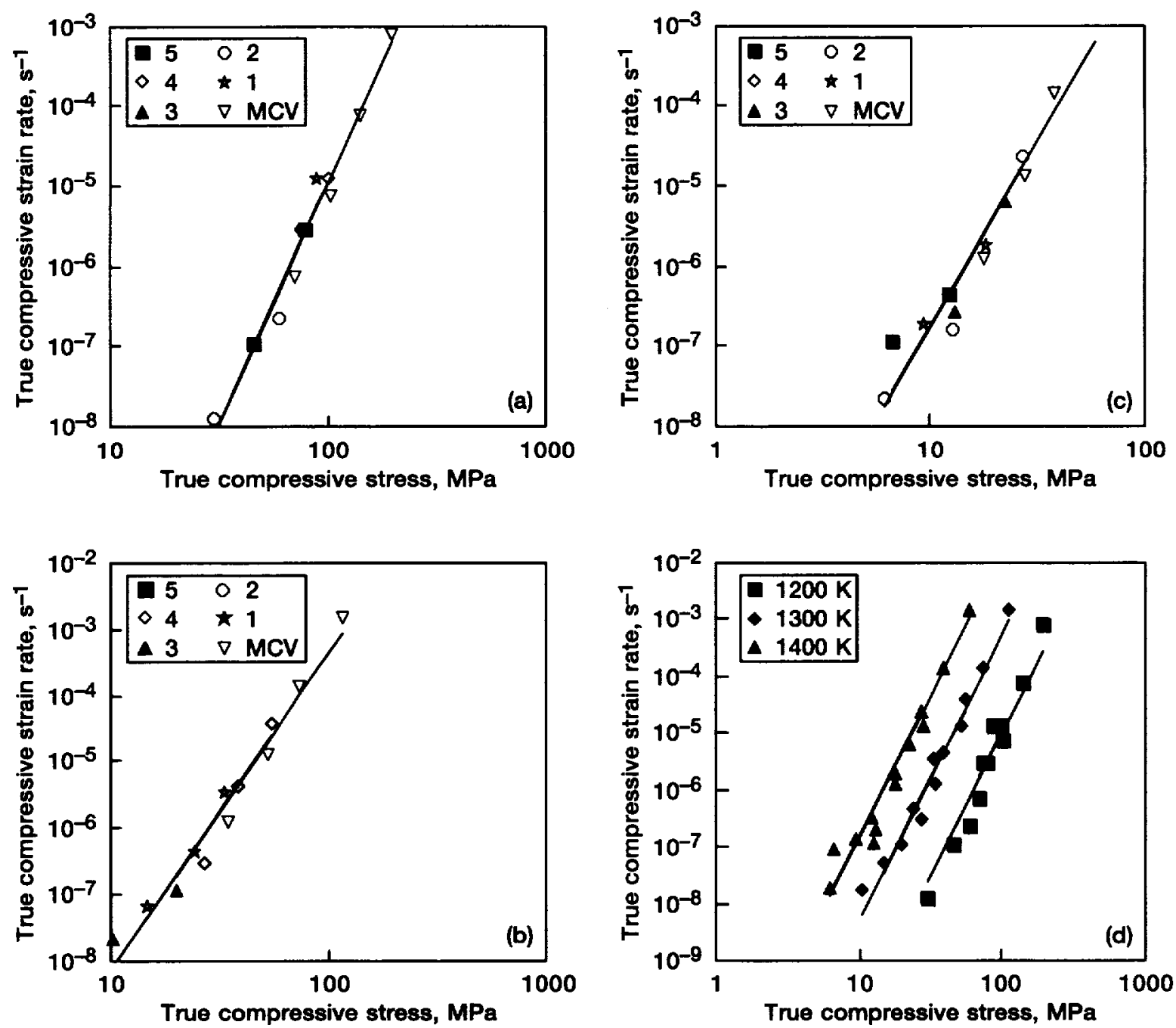

Figure 7.-Power law (a-c) and temperature compensated power law (d) representations of the multiple constant load and multiple constant velocity results for hot extruded ODS NiAl alloy IP 6000/1 Z 5 at (a) $1200 \mathrm{~K}$, (b) $1300 \mathrm{~K}$, (c) $1400 \mathrm{~K}$ and (d) $1200-1400 \mathrm{~K}$. The labels "1" through "5" in Parts a, b, c refer to the individual specimens tested under multiple temperature-constant load conditions, while the label "MCV" signify results from multiple constant velocity testing at a single temperature. 

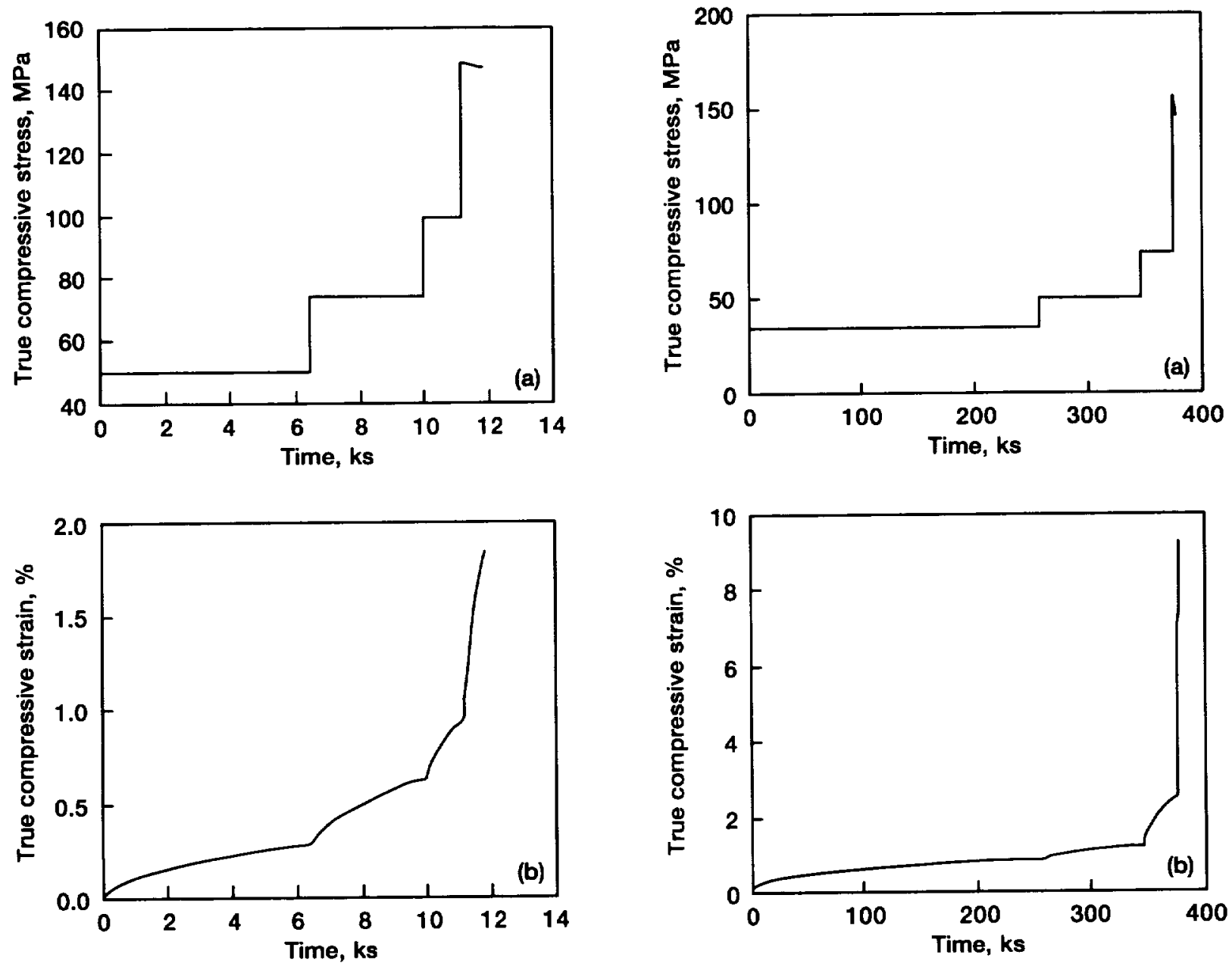

Figure 8.-True compressive stress (a) and true compressive strain (b) as a function of time from multiple temperature-constant load compressive testing of $\mathrm{N}_{2}$-roasted, hot extruded Z 5: specimen $\mathrm{Z}$ 5-N-1. The test temperature, flow stress and deformation rate for each portion of the experiment are given in Table A-II (a).

Figure 9.-True compressive stress (a) and true compressive strain (b) as a function of time from multiple temperature-constant load compressive testing of $\mathrm{N}_{2}$-roasted, hot extruded Z 5: specimen Z 5-N-2. The test temperature, flow stress and deformation rate for each portion of the experiment are given Table A-II (a). 

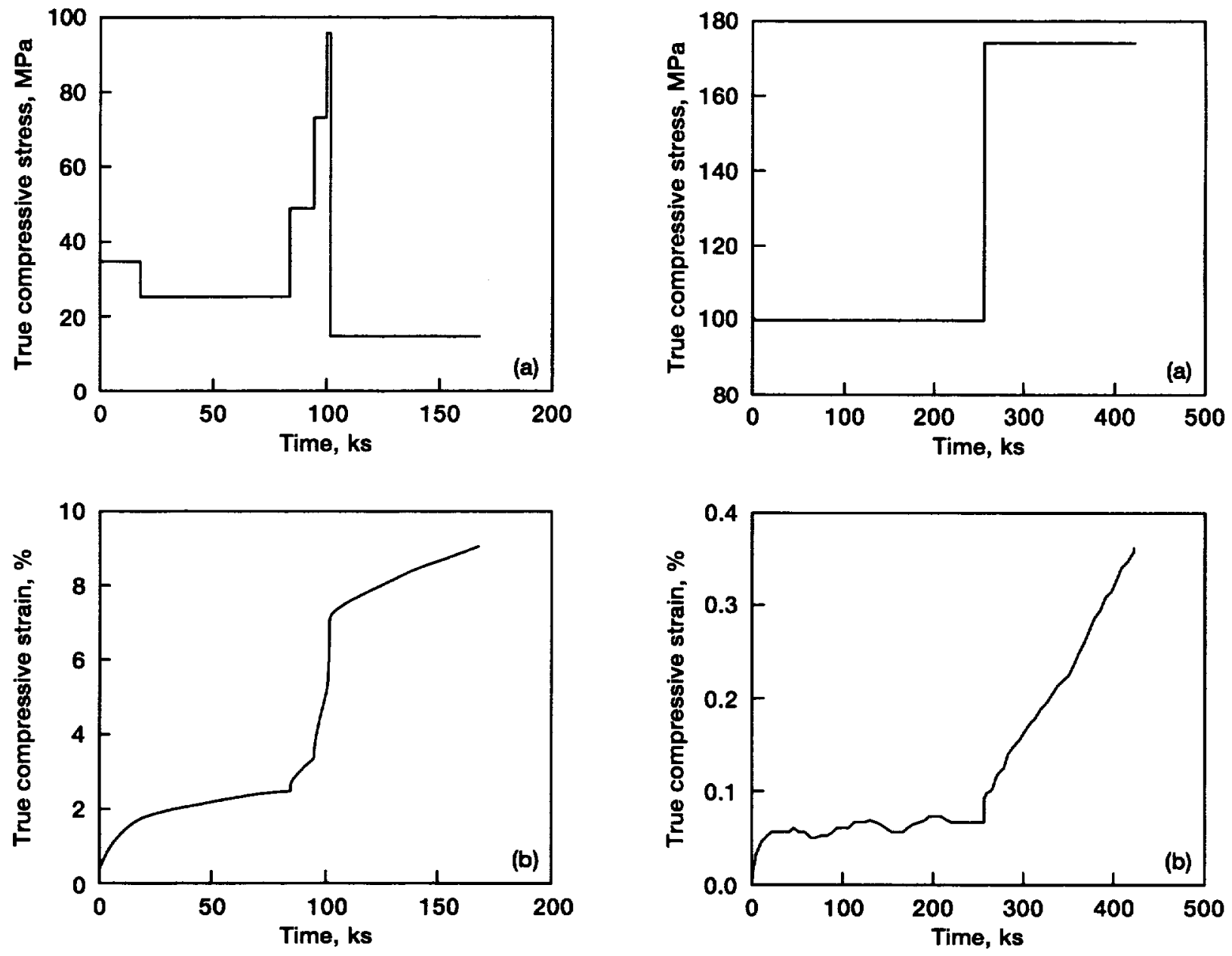

Figure 10.-True compressive stress (a) and true compressive strain (b) as a function of time from multiple temperature-constant load compressive testing of $\mathrm{N}_{\mathbf{2}}$-roasted, hot extruded Z 5: specimen Z 5-N-4. The test temperature, flow stress and deformation rate for each portion of the experiment are given Table A-II (a). 

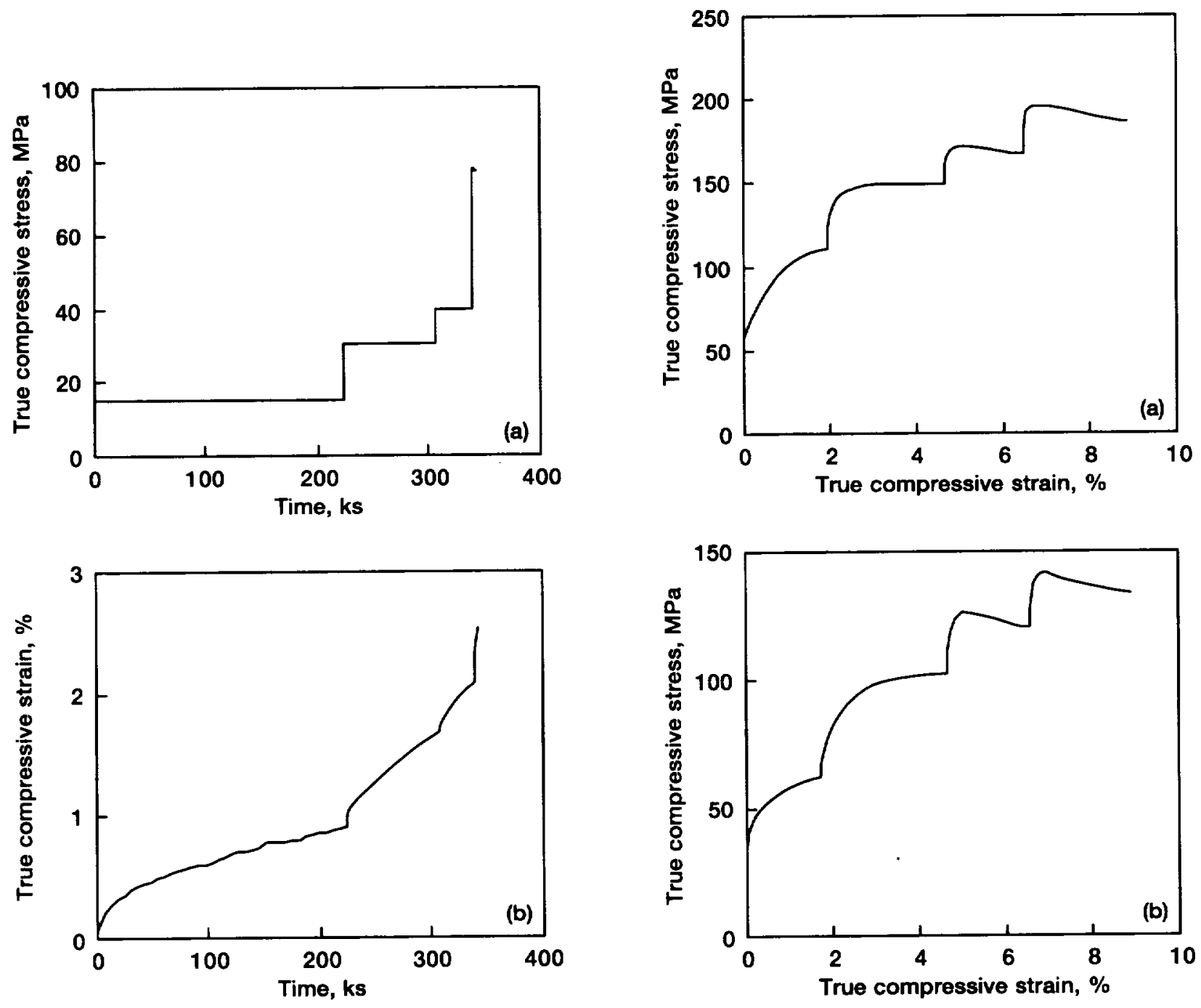

Figure 12.-True compressive stress (a) and true compressive strain (b) as a function of time from multiple temperature-constant load compressive testing of $\mathrm{N}_{2}$-roasted, hot extruded Z 5: specimen Z 5-N-6. The test temperature, flow stress and deformation rate for each portion of the experiment are given Table A-II (a). 

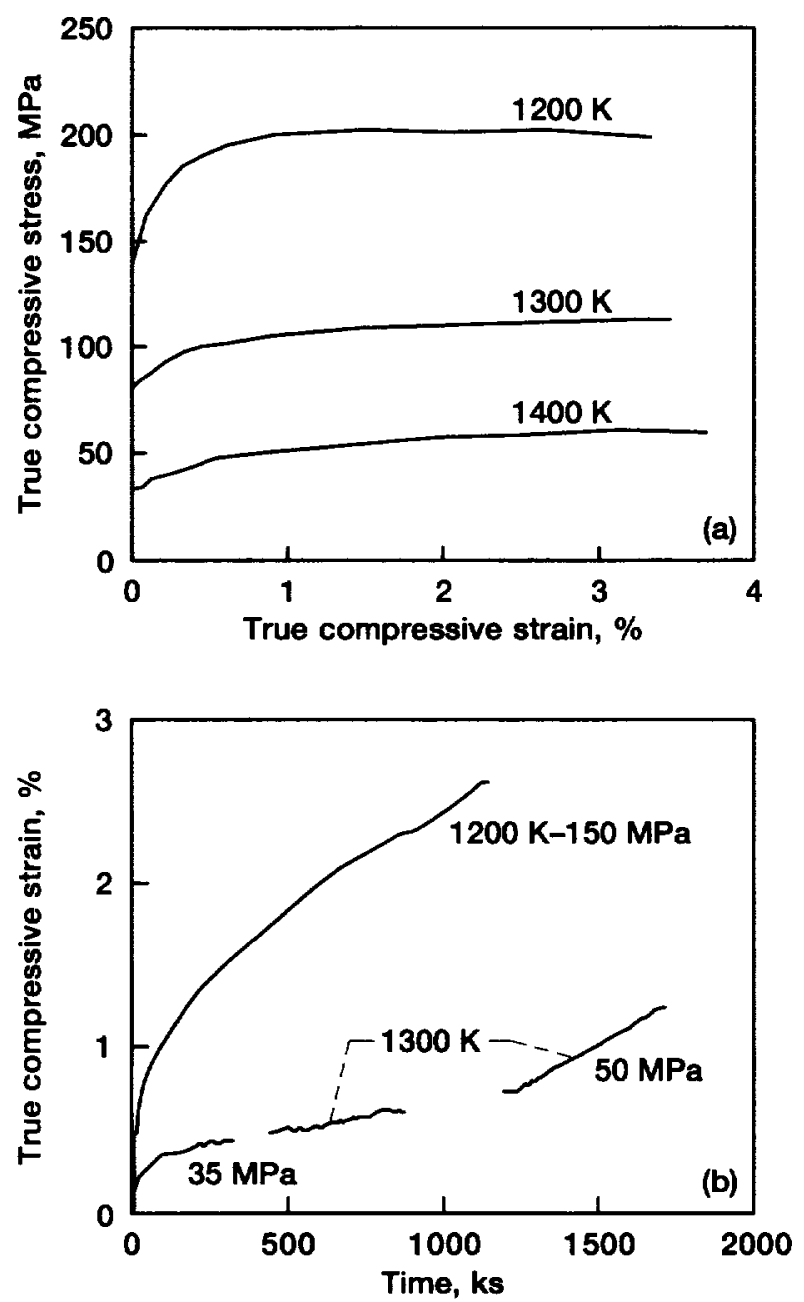

Figure 14.-True compressive stress-strain curves measured at an imposed cross head speed of $6.35 x^{-6} \mathrm{~mm} / \mathrm{s}(\mathrm{a})$ and constant load creep curves (b) for $\mathrm{N}_{2}$-roasted, hot extruded Z 5. All tests conducted on $4 \mathrm{~mm}$ diameter by $8 \mathrm{~mm}$ long samples. The test temperature, flow stress and deformation rate for each portion of the experiment are given Tables A-II (c, d). 

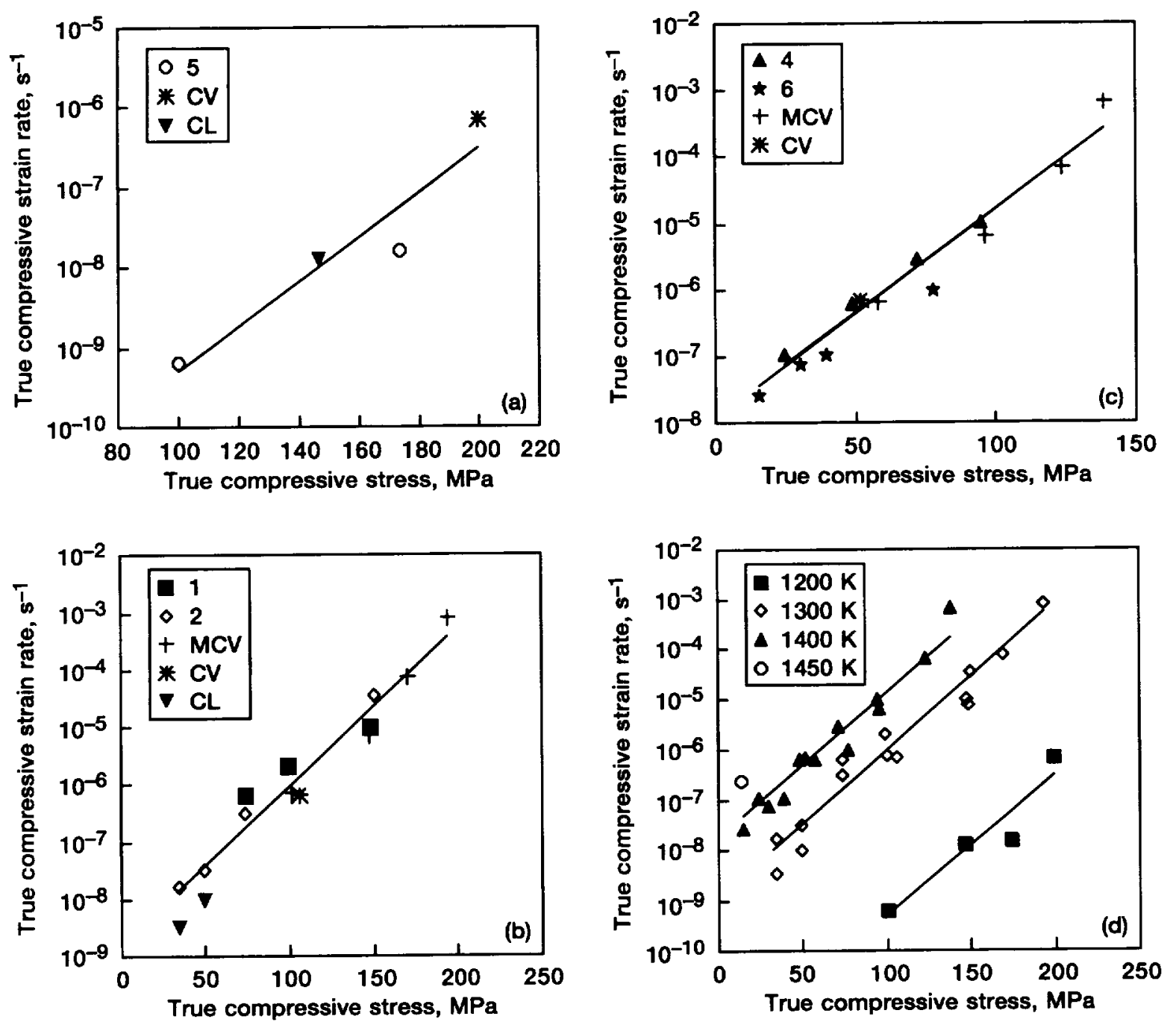

Figure 15.-Exponential law (a-c) and temperature compensated exponential law (d) representations of the flow stress-strain rate-temperature results for $\mathrm{N}_{2}$-roasted, hot extruded $Z 5$ at (a) $1200 \mathrm{~K}$ (b) $1300 \mathrm{~K}$, (c) $1400 \mathrm{~K}$ and (d) $1200-1450 \mathrm{~K}$. The labels " 1 through 6" in Parts $(\mathrm{a}, \mathrm{b}, \mathrm{c}$ ) refer to the individual specimens tested under multiple constant load conditions; "CL" indicates a compressive creep test under a constant load; "MCV" signifies samples compressed under multiple constant velocity conditions; and "CV" refers to the result from a single constant velocity test. 

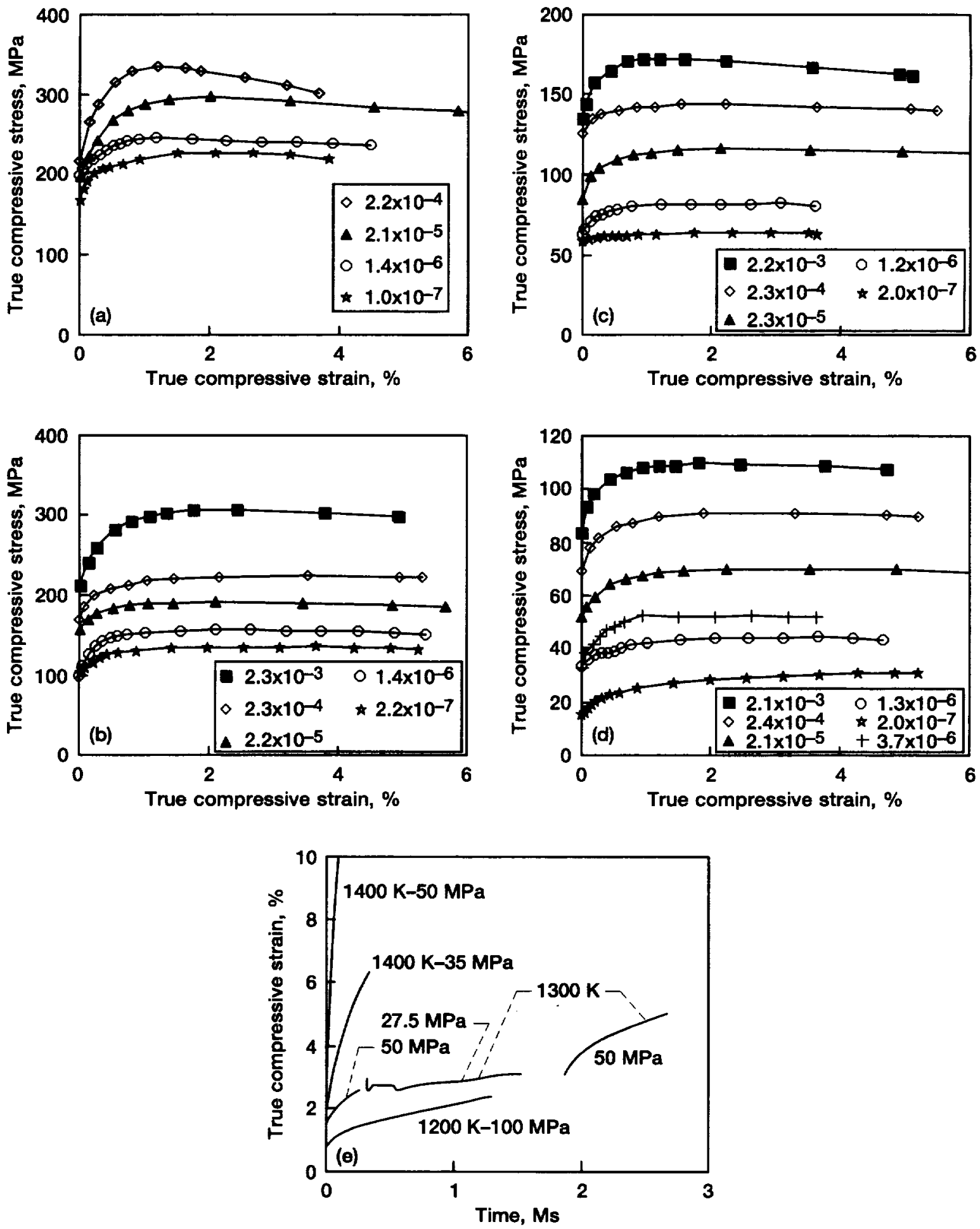

Figure 16. - True compressive stress-strain curves from single value constant velocity testing at (a) $1100 \mathrm{~K}$, (b) $1200 \mathrm{~K}$, (c) $1300 \mathrm{~K}$ and (d) $1400 \mathrm{~K}$ and (e) true compressive creep curves as a function of test temperature and engineering stress for cryomilled, hot extruded $Z 5$. The test temperature, flow stress and deformation rate from each experiment are given Tables A-III (a, b). 


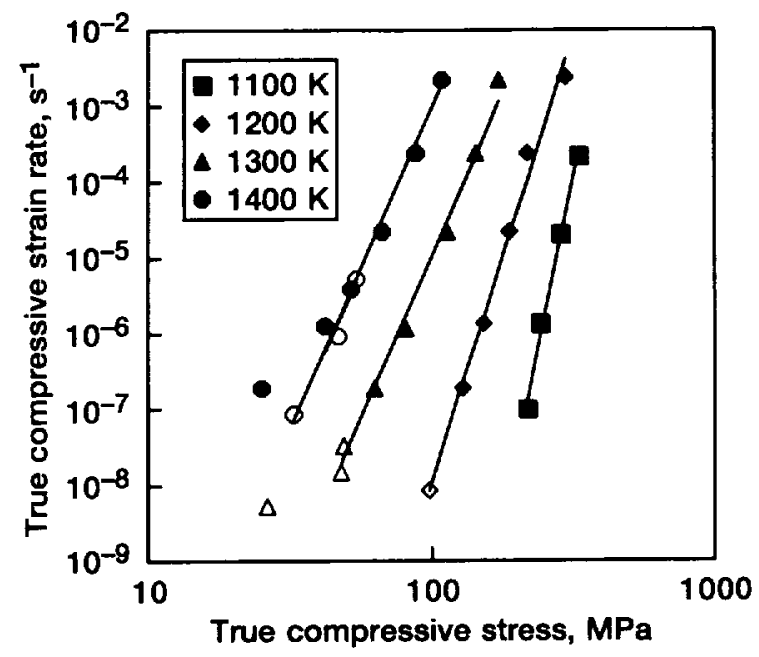

Figure 17.-True compressive flow stress-strain rate-temperature results for cryomilled, hot extruded Z 5. The solid symbols represent constant velocity results and the open symbols signify the creep test data.
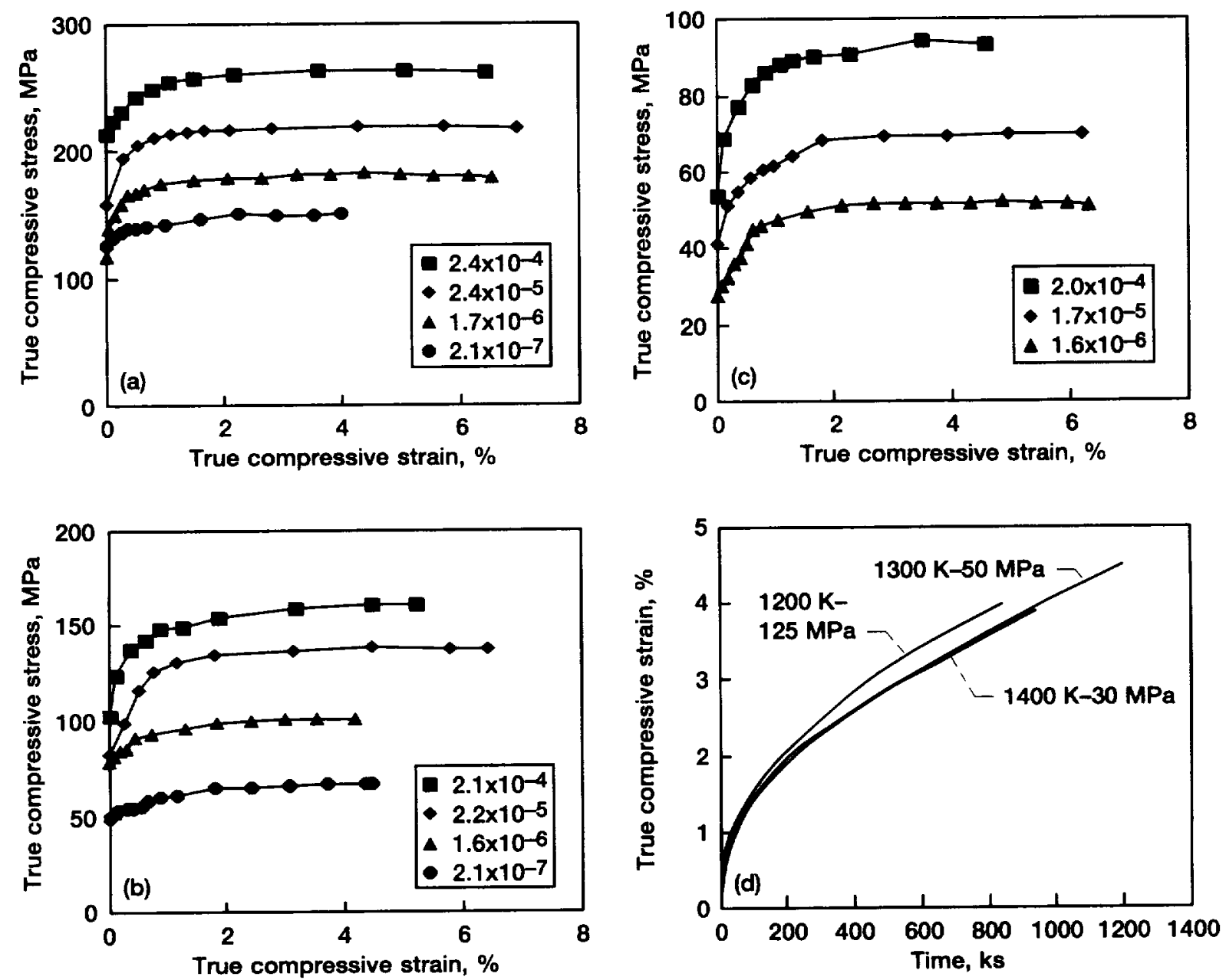

Figure 18. - True compressive stress-strain curves from single value constant velocity testing at (a) $1200 \mathrm{~K}$, (b) $1300 \mathrm{~K}$, (c) $1400 \mathrm{~K}$ and (d) true compressive creep curves as a function of test temperature and engineering stress for cryomilled, hot extruded $\{12+Z 13+Z 6 / 1\}$. The test temperature, flow stress and deformation rate from each experiment are given Tables A-IV $(a, b)$. 


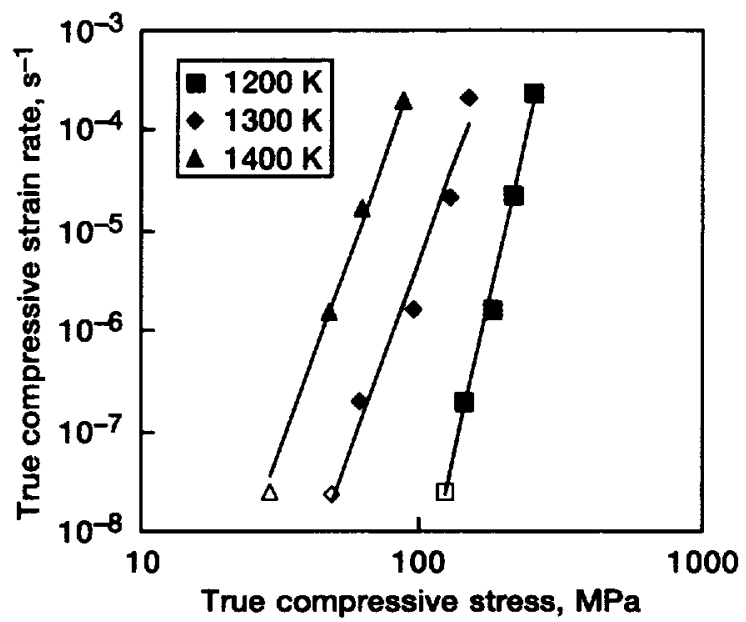

Figure 19.-True compressive flow stress-strain rate-temperature results for cryomilled, hot extruded $\{Z 12+Z 13+Z 6 / 1\}$. The solid symbols represent constant velocity results and the open symbols signify the creep test data.
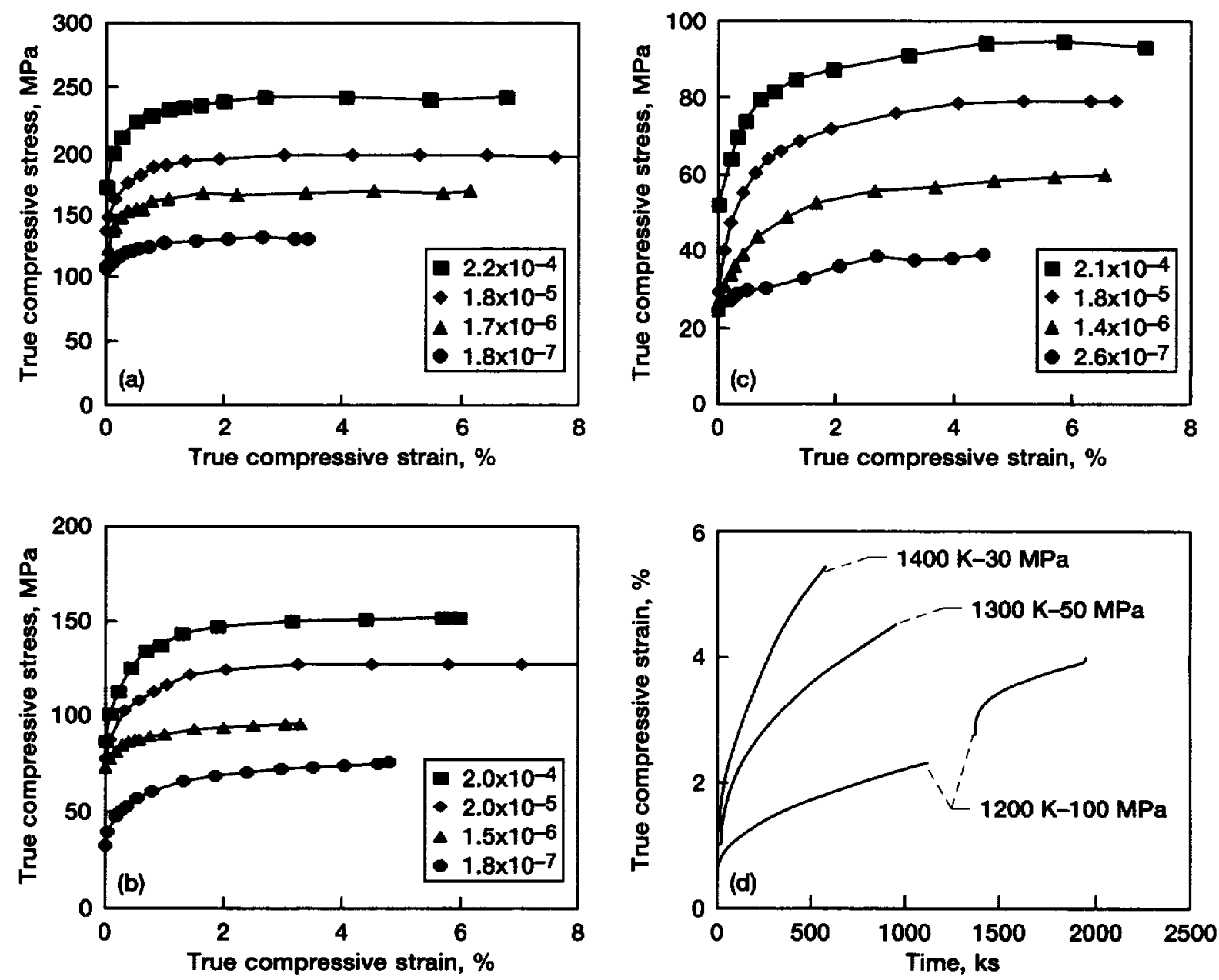

Figure 20.-True compressive stress-strain curves from single value constant velocity testing at (a) $1200 \mathrm{~K}$, (b) $1300 \mathrm{~K}$, (c) $1400 \mathrm{~K}$ and (d) true compressive creep curves as a function of test temperature and stress for cryomilled, hot extruded Z 15. The test temperature, flow stress and deformation rate from each experiment are given Tables A-V $(a, b)$. 


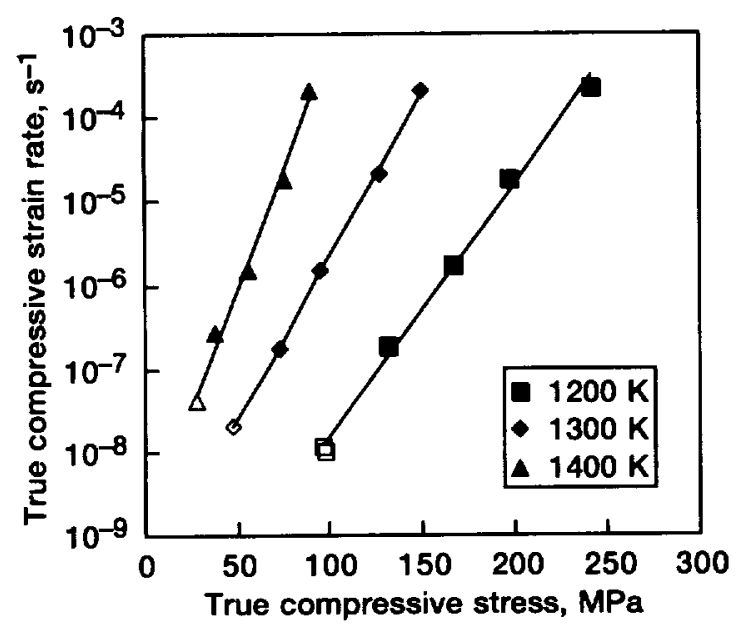

Figure 21.-True compressive flow stress-strain rate-temperature results for cryomilled, hot extruded Z 15. The solid symbols represent constant velocity results and the open symbols signify the creep test data.

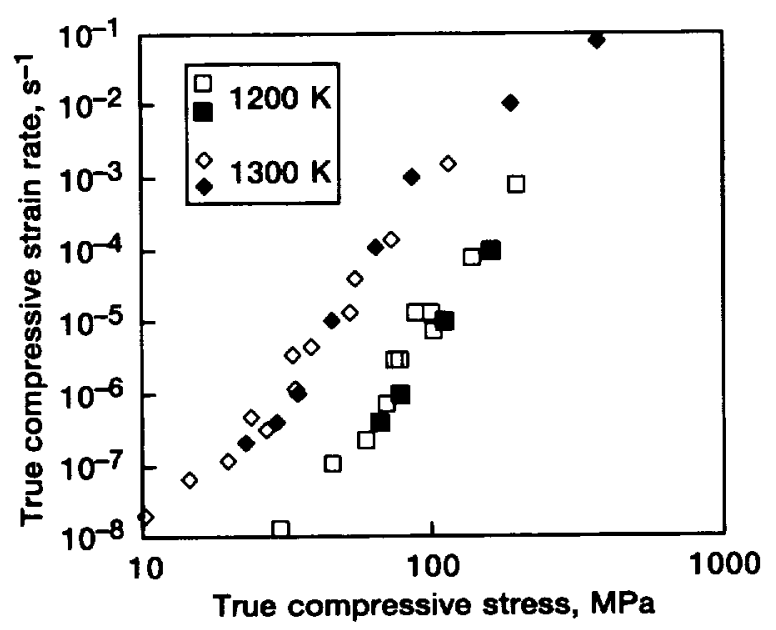

Figure 22.-Comparison of the true compressive flow stress-strain rate results at 1200 and $1300 \mathrm{~K}$ for hot extruded IP 6000/1 Z 5 (open symbols) and HIP'ed IP 6002 (ref. 5) (solid symbols). 

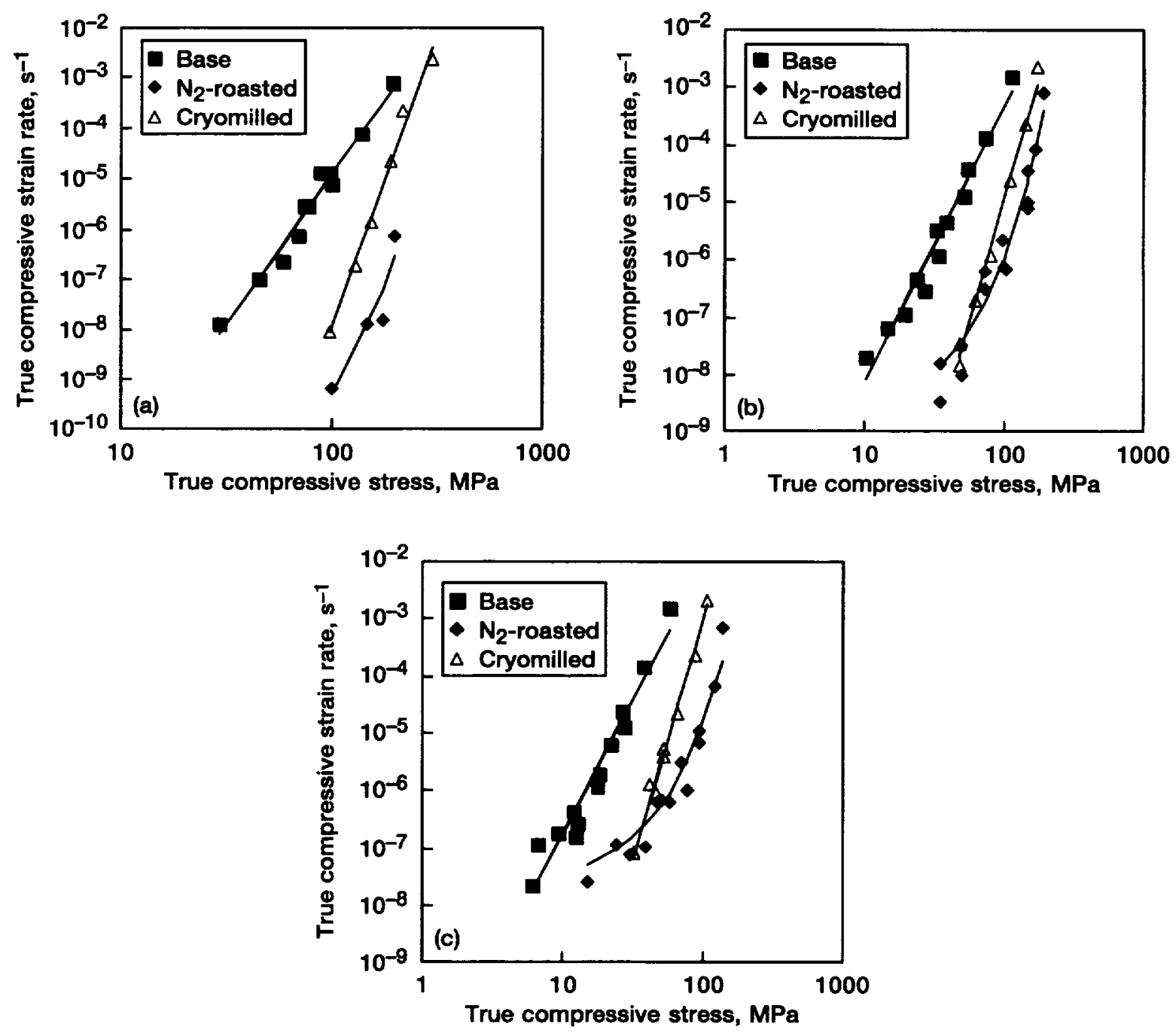

Figure 23.-Comparison of the true compressive flow stress-strain rate results for the three forms of hot extruded $Z 5$ at (a) $1200 \mathrm{~K}$, (b) $1300 \mathrm{~K}$ and (c) $1400 \mathrm{~K}$. 

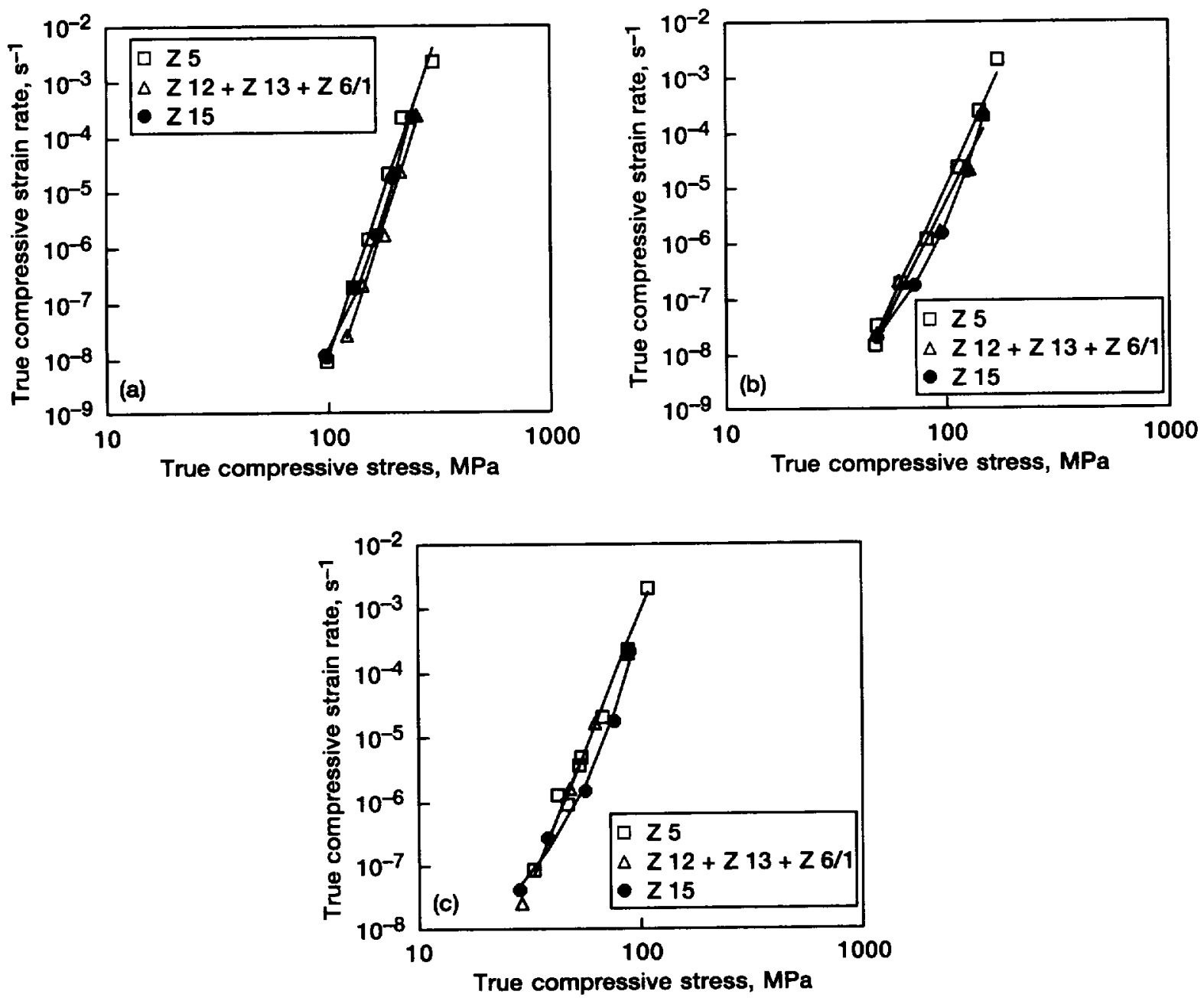

Figure 24. - Comparison of the true compressive flow stress-strain rate results for the three lots of cryomilled, hot extruded ODS NiAl at (a) $1200 \mathrm{~K}$, (b) $1300 \mathrm{~K}$ and (c) $1400 \mathrm{~K}$. 

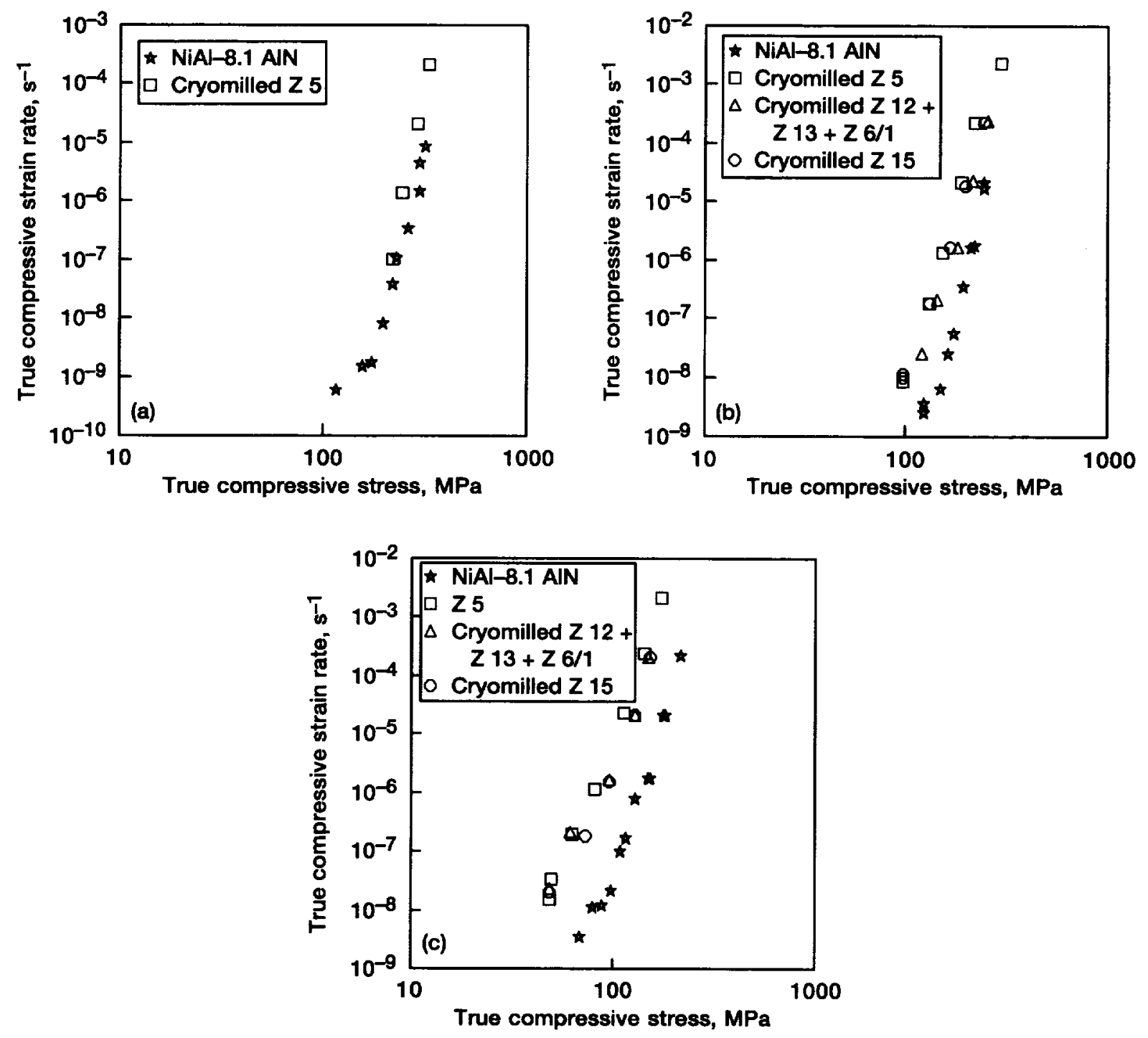

Figure 25.-Comparison of the true compressive flow stress-strain rate results for cryomilled ODS NiAI and cryomilled NiAl (ref. 11) at (a) $1100 \mathrm{~K}$, (b) $1200 \mathrm{~K}$ and (c) $1300 \mathrm{~K}$. Both cryomilled alloys contain $\sim 8$ vol $\%$ AIN. 


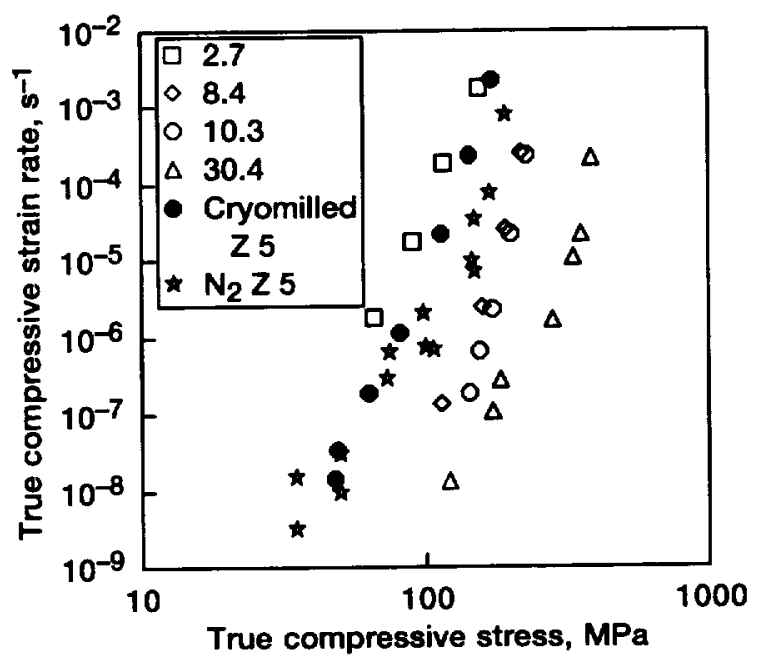

Figure 26.-Comparison of the $1300 \mathrm{~K}$ strength compressive flow stress-strain rate properties of cryomilled Z $5(\mathrm{Ni}-42 \mathrm{Al}+8.2 \mathrm{AIN})$ and $\mathrm{N}_{2}$-roasted $\mathrm{Z} 5$ (Ni-38Al + 17.6 AIN) with those measured on cryomilled binary NiAl's containing various amounts of AIN: $\mathrm{Ni}-47 \mathrm{Al}+2.7 \mathrm{AIN}, \mathrm{Ni}-47 \mathrm{Al}+8.4 \mathrm{AlN}$, $\mathrm{Ni}-47 \mathrm{Al}+10.3$ AIN and $\mathrm{Ni}-48 \mathrm{Al}+30.4$ AIN (ref. 13). 
Public reporting burden for this collection of information is estimated to average 1 hour per response, including the time for reviewing instructions, searching existing data sources, gathering and maintaining the data needed, and completing and reviewing the collection of information. Send comments regarding this burden estimate or any other aspect of this collection of information, including suggestions for reducing this burden, to Washington Headquarters Services, Directorate for Information Operations and Reports, 1215 Jefferson Davis Highway, Suite 1204, Arlington, VA 22202-4302, and to the Office of Management and Budget, Papenwork Peduction Project (0704-0188), Washington, DC 20503.

\begin{tabular}{|l|l|l}
\hline 1. AGENCY USE ONLY (Leave blank) & $\begin{array}{c}\text { 2. REPOAT DATE } \\
\text { July } 1998\end{array}$ & $\begin{array}{r}\text { 3. REPORT TYPE AND DATES COVERED } \\
\text { Technical Memorandum }\end{array}$ \\
\hline
\end{tabular}

\section{TITLE AND SUBTITLE}

5. FUNDING NUMBERS

Elevated Temperature Compressive Strength Properties of Oxide Dispersion

Strengthened NiAl After Cryomilling and Roasting in Nitrogen

6. AUTHOR(S)

J. Daniel Whittenberger, Peter Grahle, Eduard Arzt, and Mohan Hebsur

7. PERForming ORgANIZATION NAME(S) AND ADDRESS(ES)

National Aeronautics and Space Administration

Lewis Research Center

Cleveland, Ohio 44135-3191

WU-523-21-13-00

National Aeronautics and Space Administration

Washington, DC 20546-0001

8. PERFORMING ORGANIZATION REPORT NUMBER

E-11168

\section{SPONSORING/MONITORING AGENCY NAME(S) AND ADDRESS(ES)}

10. SPONSORINGMONITORING AGENCY REPORT NUMBER

NASA TM-1998-208399

\section{SUPPLEMENTARY NOTES}

J. Daniel Whittenberger, NASA Lewis Research Center; Peter Grahle and Eduard Arzt, Max-Planck-Institut für Metallforschung, Stuttgart, Germany; Mohan Hebsur, Ohio Aerospace Institute, Cleveland, Ohio 44142. Responsible person, J. Daniel Whittenberger, organization code 5120, (216) 433-3196. E-mail: John.D.Whittenberger@ lerc.nasa.gov

12a. DISTRIBUTIONAVAILABILTTY STATEMENT 12b. DISTRIBUTION CODE

Unclassified - Unlimited

Subject Category: 27

Distribution: Nonstandard

This publication is available from the NASA Center for AeroSpace Information, (301) 621-0390.

13. ABSTRACT (Maximum 200 words)

In an effort to superimpose two different elevated temperature strengthening mechanisms in NiAl, several lots of oxide dispersion strengthened (ODS) NiAl powder have been cryomilled in liquid nitrogen to introduce AIN particles at the grain boundaries. As an alternative to cryomilling, one lot of ODS NiAl was roasted in nitrogen to produce AlN. Both techniques resulted in hot extruded AlN-strengthened, ODS NiAl alloys which were stronger than the base ODS NiAl between 1200 and $1400 \mathrm{~K}$. However neither the cryomilled nor the $\mathrm{N}_{2}$-roasted ODS NiAl alloys were as strong as cryomilled binary NiAl containing like amounts of AlN. The reason(s) for the relative weakness of cryomilled ODS $\mathrm{NiAl}$ is not certain; however the lack of superior strength in $\mathrm{N}_{2}$-roasted ODS NiAl is probably due to its relatively large AlN particles.

\begin{tabular}{|c|c|}
\hline 14. SUBJECT TERMS \\
Intermetallics; NiAl, Cryomilling; Mechanical properties; \\
$\begin{array}{c}\text { 17. SECURTY CLASSIFICATION } \\
\text { OF REPORT } \\
\text { Unclassified }\end{array}$ & $\begin{array}{c}\text { 18. SECURITY CLASSIFICATION } \\
\text { OF THIS PAGE } \\
\text { Unclassified }\end{array}$ \\
\hline
\end{tabular}

NSN 7540-01-280-5500

\section{NUMBER OF PAGES}

37

16. PAICE CODE

$\mathrm{A} 03$

20. LIMITATION OF ABSTRACT
19. SECUAITY CLASSIFICATION OF ABSTRACT Unclassified 